\title{
IgGs-Abzymes from the Sera of Patients with Systemic Lupus Erythematosus Hydrolyzed miRNAs
}

This article was published in the following Dove Press journal:

Journal of Inflammation Research

\author{
Evgeny A Ermakov $\mathbb{D}^{1,2}$ \\ Evelina M Kabirova ${ }^{1,2}$ \\ Alexey E Sizikov ${ }^{3}$ \\ Valentina $N$ Buneval,2 \\ Georgy A Nevinsky (DI) ${ }^{1,2}$ \\ 'Institute of Chemical Biology and \\ Fundamental Medicine, Siberian Division of \\ Russian Academy of Sciences, Novosibirsk \\ 630090, Russia; ${ }^{2}$ Novosibirsk State \\ University, Novosibirsk 630090, Russia; \\ ${ }^{3}$ Institute of Clinical Immunology, Siberian \\ Branch of the Russian Academy of Sciences, \\ Novosibirsk, Russia
}

Correspondence: Georgy A Nevinsky Email nevinsky@niboch.nsc.ru
Background and Objectives: Systemic lupus erythematosus (SLE) is an inflammatory disease. The sera of SLE patients contain antibodies-abzymes hydrolyzing myelin basic protein (MBP), DNA, nucleotides, and oligosaccharides. The blood of SLE patients contains an increased amount of some specific miRNAs. This study aimed to analyze a possible hydrolysis of eight microRNAs found in the blood of SLE patients with high frequency by blood antibodies-abzymes.

Patients and Methods: Using affinity chromatography of the serum proteins of SLE patients and healthy donors on protein G-Sepharose and following FPLC gel filtration, electrophoretically homogeneous IgG preparations containing no impurities of canonical RNases were obtained. These preparations were used to analyze their activity in the hydrolysis of eight miRNAs.

Results: It was shown that SLE IgGs hydrolyze very efficiently four neuroregulatory miRNAs (miR-219-2-3p, miR-137, miR-219a-5p, and miR-9-5p) and four immunoregulatory miRNAs (miR-326, miR-21-3p, miR-155-5p, and miR-146a-3p). To demonstrate that the miRNAs hydrolysis is an intrinsic property of SLE IgGs, several rigid criteria were checked. Only some IgGs of healthy donors showed very weak, but reliably detectable activity in the hydrolysis miRNAs. The average activity of SLE patients IgGs according to median values is statistically significant 84.8-fold higher than that of healthy donors. The maximum and comparable average activity (RA) was observed in the hydrolysis of three miRAs: miR-9-5p, miR-155-5p, and miR-326. MiR9-5p plays an important role in the development of lupus nephritis, while miR-326 activates the production of antibodies by B cells. The major and moderate specific sites of the hydrolysis of each miRNA were revealed. The hydrolysis of eight microRNAs was mostly site specific. Several SLE IgGs hydrolyzed some miRNAs demonstrating a combination of site-specific and non-specific splitting.

Conclusion: Since inflammatory processes in SLE are associated with the change in miRNAs expression, the decrease in their concentration due to hydrolysis by autoantibodiesabzymes may be important for SLE pathogenesis.

Keywords: systemic lupus erythematosus, IgG-abzymes, miRNA hydrolysis, autoimmune and inflammatory reactions

\section{Introduction}

Systemic lupus erythematosus (SLE) belongs to inflammatory autoimmune diseases and is characterized by a breakdown of immunological tolerance and the development of autoantibodies to DNA and other own different antigens. ${ }^{1,2}$ In SLE, autoantibodies are generated against many intracellular antigens including first of all to DNA that resulting in the development of inflammation and damage to numerous organs: kidneys, skin, red bone marrow, and central nervous system. 
Due to the high heterogeneity of the clinical manifestations of SLE, the detection of autoantigens of various organs does not allow to formulate the general laws of SLE pathogenesis.

It was suggested that many autoimmune diseases (AIDs) may be originated from defects in bone marrow hematopoietic stem cells (HSCs). ${ }^{3}$ The spontaneous and DNA-induced development of profound SLE in autoimmune MRL-lpr/lpr prone mice as was shown later is associated with defects associated with specific changes in the bone marrow profile of HSCs differentiation. ${ }^{4-6} \mathrm{~A}$ similar situation was revealed for EAE-prone C57BL/6 mice (experimental autoimmune encephalomyelitis of mice, which is a model of human multiple sclerosis). ${ }^{7,8}$ During spontaneous and antigens-induced development of EAE, the changes in differentiation profiles of HSCs were observed. Changes in differentiation profiles of HSCs lead to the production in SLE and EAE mice lymphocytes synthesizing auto-Abs-abzymes splitting DNA, MBP, histones, ATP, and polysaccharides. ${ }^{4-8}$

Abzymes of different AI patients can be synthesized directly to enzyme substrates acting as haptens feigning the chemical reactions transition states ${ }^{4,8}$ or to be antiidiotypic immunoglobulins against various enzymes active centers. Healthy humans demonstrate no Abs with enzymatic activities, or their activities usually on the borderline of methods sensitivity. ${ }^{4-8 .}$

Abzymes splitting these antigens were revealed in the blood of patients with several AIDS and viral diseases (SLE, multiple sclerosis (MS), polyarthritis, autoimmune thyroiditis, tick-borne encephalitis, HIV-infected patients, and some other diseases) (for review see Refs). ${ }^{9,14}$ Some of these abzymes can play a very negative role in the development of SLE and other AIDs. DNase abzymes of SLE ${ }^{15}$ and MS patients ${ }^{16}$ are harmful since they are cytotoxic, can penetrate the cell nucleus, and split nuclear DNA inducing cells death by their apoptosis. Complexes of DNA-histones are the main immunogens powerfully stimulating the formation of anti-DNA autoantibodies ${ }^{17}$ and DNase abzymes. ${ }^{9-14}$ The increase in the blood concentration of DNA and its complexes with histones leads to the production of abzymes against these antigens stimulating the development of AIDs. ${ }^{13,14}$ MBP-hydrolyzing abzymes (Abzs) are also dangerous for mammals since they attack MBP of the axon's myelin-proteolipid sheath, which can lead to impaired conduction of nerve impulses. ${ }^{13,14}$

With the development of AIDs, RNA-hydrolyzing abzymes are of particular interest. Polyclonal IgGs and
IgMs of SLE patients hydrolyze polymeric RNAs $~ 30-300-$ fold faster than DNA. ${ }^{18,19}$ However, until now it was not clear to which blood RNAs exactly these abzymes may be produced and how they can be sequence-specific.

Non-coding microRNAs (miRNAs) play a special role in living organisms since they regulate transcription and expression of many genes ${ }^{20,23}$ as well as important for neuroinflammation. ${ }^{22}$ Several specific miRNAs are characterized by increased expression in the blood of SLE patients. $^{24,25}$ The extracellular miRNAs possess several functions: cell proliferation, signaling between cells, regulation of neurogenesis, and angiogenesis. ${ }^{26}$ Pathological processes resulting in inflammatory processes in SLE patients are associated with the change in miRNAs expression. ${ }^{27}$ Taking into account a special role of miRNAs, it was interesting whether auto-Abs-abzymes against these miRNAs may be generated.

The first data on the synthesis of Abs against miRNAs specifically hydrolyzing some miRNAs were found in the blood sera of schizophrenia (SCZ) patients. ${ }^{28,29}$ Hydrolysis of miR-219a-5p, miR-137, miR-219-2-3p, and miR-9-5p playing an important role in the functioning and regulation of several genes of SCZ patients was analyzed. Interestingly, the hydrolysis of these miRNAs was site-specific. ${ }^{28,29}$

According to modern data, the availability of abzymes in the blood sera is a clear statistically significant sign of the beginning and following progress of different AIDS in mammals. In the blood of patients with SCZ, as well as SLE, were discovered abzymes that hydrolyze DNA, RNA, and MBP. ${ }^{28-31}$ Thus, schizophrenia, like SLE, may be also considered as an autoimmune disease. ${ }^{28-32}$ In addition, London Medical Institute Oliver House scientists put forward the idea that schizophrenia is an autoimmune disease of the brain. ${ }^{32}$ Some similar neuropsychiatric indicators of SCZ and $50 \%$ of SLE patients were shown to be common. ${ }^{33}$ Therefore, it was interesting to see if the abzymes hydrolyzing miRNAs that were found in SCZ can exist in patients with SLE and how much they may differ or be similar.

In this article, we analyzed the possible relative activity of SLE IgGs and compare their substrate specificity in the hydrolysis of microRNAs with those for Abs from SCZ patients.

\section{Patients and Methods}

\section{Chemicals, Donors, and Patients}

Most chemicals were bought from Sigma (USA, St. Louis, MO), Superdex 200 HR 10/30 columns from GE Healthcare 
(USA, GE Healthcare Life Sciences). Thermosensitive alkaline phosphatase (FastAP) and RNase A were from Fisher Scientific (USA, Pittsburgh, PA).

Blood sera samples of patients with SLE and healthy volunteers were from the Institute of Clinical Immunology (Novosibirsk, Russia).

The blood sera of eleven SLE patients of different ages (39-68 yr. old; average value $51.0 \pm 10.5 ; 9$ women and $1 \mathrm{man})$ and 14 healthy volunteers (18-40 yr. old; average

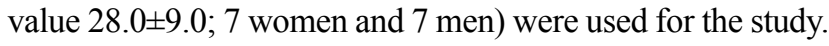

The study protocol was approved by the Institute of Clinical Immunology ethics committee including the written consent of patients and healthy donors to present their blood for scientific purposes (according to guidelines of the Helsinki ethics committee). The diagnosis of SLE was made on the basis of the following tests: complete blood count (erythrocyte sedimentation rate, a decrease in the number of white blood cells, platelets, red blood cells), concentrations of C-reactive protein, antinuclear factor, antibodies to DNA, phospholipids, Ro/SS-A, La/SS-B, Smith antigen, changes in components of the C3, C4 complement system, analysis of urine, ultrasound examination of the carotid arteries, abdominal organs and joints. An analysis was made of kidney damage, neuropsychiatric lesions, hemolytic anemia. Clinical criteria were also considered: mucosal ulcers, a rash on the cheekbones, bullous rashes, toxic epidermal necrosis as a variant of SLE, maculopapular rash, photosensitivity (skin rash resulting from a reaction to sunlight), subacute skin lupus.

SLE patients and healthy donors had no symptoms of any acute bacterial or viral infections.

\section{$\lg G$ Purification and Characterization}

Electrophoretically homogeneous IgGs first were separated from other sera proteins by affinity chromatography of serum samples on protein G-Sepharose and following FPLC gel filtration using acidic buffer ( $\mathrm{pH}$ 2.6) as in $^{28,32,34-37}$. A more detailed description of the procedures used is given in the Supplementary methods. After all studies of IgG purification, collected fractions were neutralized and sterilized by samples filtration through $0.1 \mu \mathrm{m}$ Millex filter.

For checking of strict criteria assigning RNase activity directly to antibodies, mixtures of eleven preparations of SLE IgGs (sle-IgG $\mathrm{Imix}_{\text {mix }}$ ) and 14 samples of healthy humans $\operatorname{IgGs}\left(\mathrm{h}-\mathrm{IgG}_{\text {mix }}\right)$ were used. The sle- $\operatorname{IgG}_{\text {mix }}$ was subjected to FPLC gel filtration on a Superdex 200 column using acidic buffer ( $\mathrm{pH}$ 2.6) and affinity chromatography on anti-IgGSepharose bearing immobilized Abs against human IgGs as in ${ }^{28,32,34-37}$ Detailed descriptions of these chromatographies are given in the Supplementary methods. All fractions after two chromatographies were used to analyze their activity in different RNAs hydrolysis as described below.

For comparison of SLE IgGs and RNase A thermal stability, they were preincubated for $15 \mathrm{~min}$ at different temperatures from $30^{\circ} \mathrm{C}$ to $99^{\circ} \mathrm{C}$ and then their relative activities (RAs) were analyzed as described below using miR-137 as the substrate.

\section{Analysis of Homo-Oligonucleotides and miRNAs Hydrolysis by IgGs}

Fluorescently (fluorescein isothiocyanate; Flu) labeled homoribooligonucleotides (ribo-ONs) 5'-Flu-(pC) $)_{23}, 5^{\prime}$-Flu-(pA) $)_{23}$, $5^{\prime}$-Flu-(pU $)_{23}$, and several miRNAs characterized by impaired expression in SLE patients were used in the study. Four neuroregulatory miRNAs are: miR-219a-5p (5'-Flu- UGAU UGUCCAAACGCAAUUCU), miR-137 (5'-Flu-UUAUU GCUUAAGAAUACGCGUAG), miR-219-2-3p

(5'-Flu-AGAAUUGUGGCUGGACAUCUGU), and miR-9-5p (5'-Flu-UCUUUGGUUAUCUAGCUGUAU GA) and four immunoregulatory miRNas are: $\mathrm{miR}-326$ (5'- Flu-CCUCUGGGCCCUUCCUCCAG), miR-155-5p (5'- Flu-UUAAUGCUAAUCGUGAUAGGGGU), miR21-3p (5'- Flu-CAACACCAGUCGAUGGGCUGU), and miR-146a-3p (5'-Flu-CCUCUGAAAUUCAGUUCUUC AG).

All reaction mixtures $(10 \mu \mathrm{L})$ contained $50 \mathrm{mM}$ Tris- $\mathrm{HCl}$ buffer (pH 7.5), $0.01 \mathrm{mg} / \mathrm{mL}$ one of miRNAs $(1.3-1.6 \mu \mathrm{M}$ depending on the microRNA used) and $0.6 \mu \mathrm{M}$ individual IgGs as in. ${ }^{29,30}$ They were incubated for $1 \mathrm{~h}$ at $37^{\circ} \mathrm{C}$ and reactions were stopped by adding of $10 \mu \mathrm{L}$ of denaturing buffer $(0.025 \%$ xylene cyanol in a solution of $8 \mathrm{M}$ urea). RNA length markers were prepared by statistical alkaline hydrolysis of $3.2 \mu \mathrm{M}$ miRNAs by their hydrolysis for $15 \mathrm{~min}$ at $95^{\circ} \mathrm{C}$ using $50 \mathrm{mM}$ bicarbonate buffer ( $\left.\mathrm{pH} 9.5\right)$.

\section{Spatial Model of microRNAs}

The spatial models of four microRNAs (miR-137, miR9-5p, miR-219-2-3p, and miR-219a-5p) were generated previously ${ }^{28,29}$ and for the other four miRNAs (miR-326, miR-155-5p, miR-21-3p, and miR-146a-3p) were calculated in this article by Predict a Secondary Structure server: http://rna.urmc.rochester.edu/RNAstructureWeb/ $\underline{\text { Servers/Predict1/Predict1.html. }}$ 


\section{Statistical Analysis}

Shapiro-Wilk's W-Test criterion was used to analyze a normality of the distribution of different value sets obtained. The RAs of miRNAs hydrolysis for some IgG sample sets did not correspond to the normal Gaussian distribution. The nonparametric ranking method of Spearman therefore was used for the correlation analysis. The possible differences between the sample sets were analyzed by the Mann-Whitney U-test; the sets demonstrating $P<0.05$ were considered as statistically different. The average values \pm SD, median magnitudes $(M)$ and interquartile ranges (IQR) were estimated.

\section{Results}

Eleven IgG preparations were isolated from the blood sera of patients with a reliably established SLE diagnosis. In several articles, it was shown earlier (1995-2000 years) that antibodies from blood sera of healthy humans (with very rare exception) usually could not hydrolyze polymeric RNAs. ${ }^{10-14,37,39}$ However, a change has occurred over the last 20 years in the diet of people and environmental pollution was increased. Taking this into account, for control in this work in the analysis of ribo-ONs and miRNAs-hydrolyzing activities we have used 14 preparations from the blood of conditionally healthy donors.

\section{Selection of microRNA for Analysis}

Numerous miRNAs are involved in regulating inflammation, which can be conditionally divided into proinflammatory and anti-inflammatory. ${ }^{21}$ Micro-RNAs that predominantly inhibit the expression of anti-inflammatory genes and thus stimulate pro-inflammatory responses are called pro-inflammatory miRNAs. On the contrary, antiinflammatory miRNAs inhibit the expression of proinflammatory genes. Key pro-inflammatory miRNAs include miR-155-5p and miR-326. ${ }^{21}$ MiR-155 promotes the development of inflammatory $\mathrm{T}$ helper 1 (Th1) and T helper 17 (Th17) cells. ${ }^{40}$ Also, miR-155 is required for proper $\mathrm{T}$ cell-dependent antibody response, $\mathrm{B}$ cell function, and cytokine production. ${ }^{41} \mathrm{MiR}-326$ is a crucial regulator of pro-inflammatory Th17 cells differentiation, affecting the transcription factor Ets-1. ${ }^{42}$ At the same time, anti-inflammatory miRNAs were found, which include miR-146a and miR-21. ${ }^{21}$ It is known that miR146a-3p inhibits $\mathrm{T}$ helper cells differentiation and type I interferon synthesis by blocking the IRF5 and STAT-1 proteins $^{43,44}$ therefore, a decrease in miR-146a-3p expression promotes the development of SLE. Through RASGRP1 (RAS guanyl nucleotide-releasing protein 1), miR-21-3p inhibits DNA methylation enzyme, DNA methyltransferase 1, leading to enhanced expression genes associated with the autoimmune response. ${ }^{44}$ Therefore, a decrease in miR-21 expression contributes to autoimmune pathology.

Dysregulation of the expression of pro-inflammatory miRNAs (miR-155-5p and miR-326) and antiinflammatory miRNAs (miR-146a and miR-21) has been shown in SLE. It was revealed that anti-inflammatory miR21-3p and miR-146a-3p are overexpressed in peripheral blood mononuclear cells (PBMCs) of SLE patients compared to healthy subjects. ${ }^{45}$ However, other studies showed a decrease in miR-146a expression in PBMCs and plasma of SLE patients. ${ }^{24,46}$ At the same time, the expression of pro-inflammatory miR-155-5p and miR-326 was significantly increased in PBMCs of SLE patients. ${ }^{45}$ Besides, the expression level of miR-326 was higher in regulatory $\mathrm{T}$ (Treg) cells isolated from SLE patients compared to healthy individuals. ${ }^{47}$ The increase in miR-326 expression was accompanied by a decrease in Ets-1, which is a negative regulator of $\mathrm{B}$ cell differentiation and autoantibodies generation. ${ }^{47}$ Given the above data on the dysregulation of miRNAs in SLE, we selected pro-inflammatory miR-155-5p and miR-326 and anti-inflammatory miR146a miR-21 as one of the key targets in our study.

SLE is known to be often accompanied by neurological symptoms. Neuroregulatory miRNAs are actively involved in the regulation of the nervous system functions. ${ }^{48}$ Therefore, we included in the study neuroregulatory miRNAs such as miR-9-5p, miR-219a-5p, miR-219-2-3p, and miR-137, which we had previously studied in schizophrenia. ${ }^{27,28}$ Among these miRNAs, miR-9-5p is also involved in the regulation of inflammation. It was shown that miR-9-5p inhibits NLRP3 inflammasome activation, ${ }^{49}$ and also participates in the regulation of nuclear factor kappa-B (NF-kB). ${ }^{50}$ Besides, miR-219 is associated with the regulation of endogenous resolution programs of inflammation. ${ }^{51}$

\section{Purification and Characterizing of IgGs}

Electrophoretically homogeneous IgG preparations were obtained from the sera of eleven SLE patients and 14 healthy conditionally healthy donors by sera proteins affinity chromatographies on Protein A-Sepharose and following FPLC gel filtration under conditions of nonspecific interactions destruction. $^{28-31}$ Two mixtures of equal amounts of 
polyclonal IgGs of 11 SLE patients (sle- $\operatorname{IgG}_{\text {mix }}$ ) and 14 healthy volunteers (healthy-IgG $\mathrm{G}_{\text {mix }}$ ) were prepared. The typical $150-\mathrm{kDa} \mathrm{IgG}_{\text {mix }}$ preparations electrophoretic homogeneity was shown by SDS-PAGE with silver staining of proteins; only one band of protein was revealed (Figure 1A).

\section{Application of the Strict Criteria}

To show RNase activity utensils directly to IgGs of SLE patients, previously developed four strict criteria were used. $^{9-14,52}$ It was shown that: a) the sle- $\operatorname{IgG}_{\text {mix }}$ and healthy- $\operatorname{IgG}_{\text {mix }}$ (corresponding to the peaks (central parts)
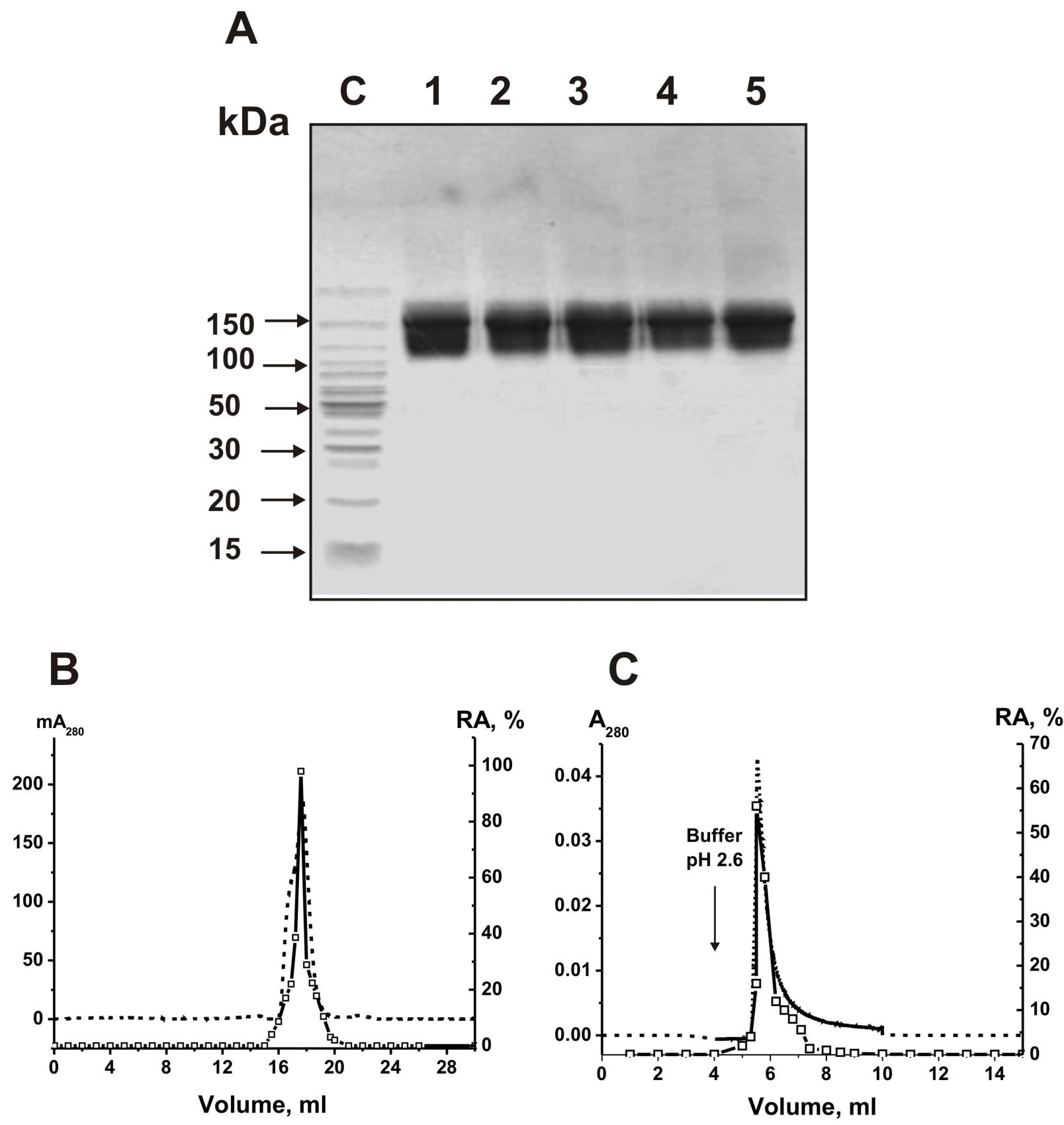

Figure I SDS-PAGE analysis of the electrophoretic homogeneity of sle-lgGI (lane I), sle-lgG2 (lane 2), sle-lgG mix (lane 3), healthy-lgGI (lane 4), and healthy-lgG in gradient gel (4-18\%) with following staining of proteins with colloid silver (I5 micro g IgGs were used) (A). Sle-lgGI, sle-lgG2, and healthy-lgGIcorrespond to individual antibodies of SLE patients and healthy volunteers, respectively. The arrows corresponding to lane $\mathrm{C}$ show the positions of protein molecular mass markers (A). Sle-lgG mix FPLC gel filtration using Superdex 200 column equilibrated with the buffer ( $\mathrm{pH} 2.6)$ after $\lg \mathrm{G}_{\text {mix }}$ pre-incubation in this buffer (B) and affinity chromatography of the sle-lgG $\mathrm{mix}$ on Sepharose conjugated with mouse lgGs against human $\operatorname{lgGs}(\mathbf{C})$ : (一), absorbance at $280 \mathrm{~nm}\left(\mathrm{~A}_{280}\right)$; ( $\square$ ), relative activity (RA, \%) of sle-lgG mix in the hydrolysis of miR-326 (B and C). A complete hydrolysis of miRNA for $8 \mathrm{~h}$ using $7 \mu \mathrm{L}$ of eluate was taken for $100 \%$ (B and $\mathbf{C}$ ). The error of the initial rate determination from two experiments in each case did not exceed $7-10 \%$. 
after gel filtration) were electrophoretically homogeneous (Figure $1 \mathrm{~A}$ and $\mathrm{B}$ ) sle- $\operatorname{IgG}_{\text {mix }}$ after gel filtration in acidic buffer ( $\mathrm{pH}$ 2.6) destroying strong interactions did not lose RNase activity and this activity peak coincided with intact IgG peak (Figure 1B and C) anti-IgG-Sepharose bind completely ribonuclease activity and the peaks of RNase activity and IgGs coincided during their specific elution by acidic buffer (pH 2.6) (Figure 1C).

Canonical mammalian ribonucleases have significantly lower molecular masses $(13-15 \mathrm{kDa})$ than the IgGs
$(150 \mathrm{kDa})$. Therefore, the concurrence of two peaks of RNase activity and IgGs directly indicate that SLE IgGs split RNAs and antibody preparations are not contaminated with canonical ribonucleases.

In addition, all canonical RNases are very thermostable enzymes, while Abs are significantly less thermostable molecules. Figure 2A demonstrates that after RNase $\mathrm{A}$ and IgGs preincubation for $15 \mathrm{~min}$, even at $100^{\circ} \mathrm{C}$, ribonuclease practically does not lose its activity, while $\mathrm{IgG}_{\text {mix }}$ activity decreases to zero.
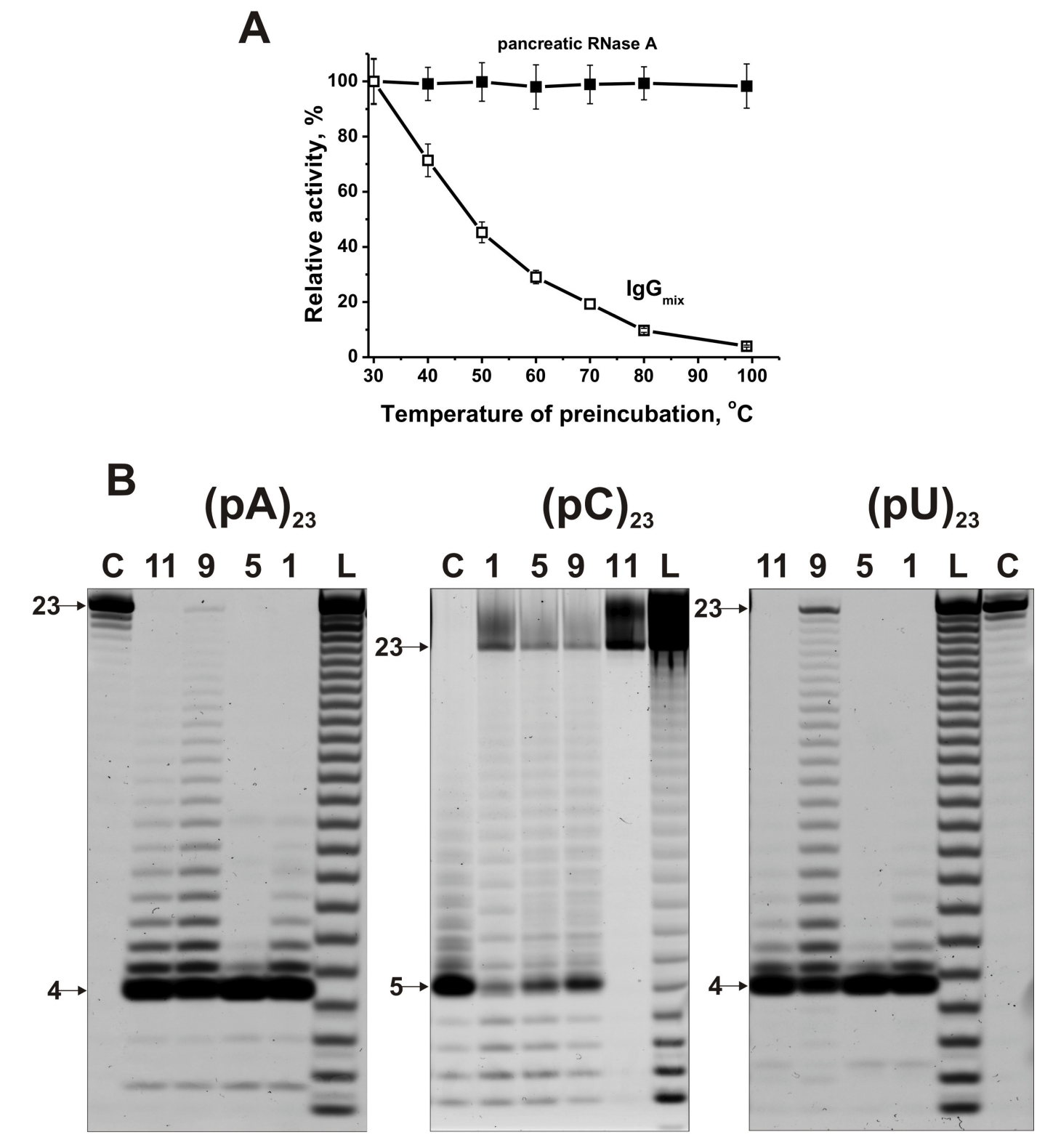

$(\mathrm{pC})_{23}$

$(\mathrm{pU})_{23}$

Figure 2 Comparison of thermal stability of human $R N a$ a $A$ and sle- $\lg G_{\text {mix }}(\mathbf{A})$. RNase $A$ and $\lg G_{\text {mix }}$ were preincubated for 15 min at different temperatures and then their

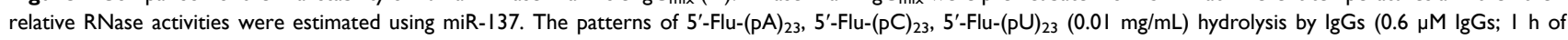
incubation) from sera of four different SLE patients (B). The products of the hydrolysis were detected due to their fluorescence of the fluorescent residue (Flu) on their $5^{\prime}$ ends. The numbers of antibodies and lengths of the products are indicated on panel (B). 


\section{Estimation of the Relative RNase Activity}

Using fluorescently labeled homo-oligonucleotides (riboONs) 5'-Flu-(pC) ${ }_{23}, 5^{\prime}$-Flu-(pA) $)_{23}, 5^{\prime}$-Flu-(pU $)_{23}$, and eight microRNAs, ribonuclease activity of IgGs was estimated quantitatively. Figure 2B demonstrates four main types of splitting patterns of three homo-ribo-ONs used. Different IgGs hydrolyze 5'-Flu-(pA) ${ }_{23}, 5^{\prime}$-Flu-(pC) $)_{23}, 5^{\prime}$-Flu-(pU $)_{23}$ either almost non-specifically at nearly all their internucleoside bonds or with the predominant formation of tetra and pentanucleotides (Figure 2B). Interestingly that in the case of $5^{\prime}$-Flu- $(\mathrm{pC})_{23}$, there is a more efficient formation of products containing from one to four nucleotide units, but pentanucleotides are major products. Thus, three homoONs hydrolysis proceeds predominantly non-specifically, but tetra and pentanucleotides are the major products for all of IgGs and ribo-ONs.

In contrast to homo-ribo-ONs, the eight miRNAs hydrolysis was predominantly site-specific. Typical patterns of four neuroregulatory miRNAs hydrolysis (miR219a-5p, miR-137, miR-219-2-3p, and miR-9-5p) are shown in Figures 3 and 4.

Typical examples of hydrolysis of miR-219a-5p by 9 of $11 \mathrm{IgGs}$ are given in Figure 3A. All nine IgGs hydrolyze this miRNA mostly at two major sites: $13 \mathrm{G}-14 \mathrm{C}$ and $9 \mathrm{C}$ $10 \mathrm{~A}$; only some of them hydrolyze RNA more effectively in $15 \mathrm{C}-16 \mathrm{~A}$ and $6 \mathrm{G}-7 \mathrm{U}$ sites. For all $11 \mathrm{MS}$ IgGs, a similar type of site-specific hydrolysis of miR-219a-5p was observed.

A different situation was observed in the hydrolysis of miR-219-2-3p with 11 IgGs (Figure 3B). All IgGs showed comparable efficacy in this miRNA hydrolysis demonstrating a combination of non-specific and site-specific splitting of this RNA (Figure 3B). In parallel with a somewhat comparable hydrolysis of almost all bonds from the first to the seventeenth nucleotide base, there were two major cleavage sites: $5 \mathrm{U}-6 \mathrm{U}$ and $2 \mathrm{G}-3 \mathrm{~A}$.

All IgGs hydrolyze miR-9-5p approximately similar demonstrating a cluster of five cleavage sites in the region from 7 th to 11 th nucleotide of this miRNA sequence (Figure 4A). The most major site of hydrolysis was $8 \mathrm{U}$ 9U. Interestingly, in this case, there was no effective miRNA cleavage at sites higher than the tenth nucleotide, and the main short product was trinucleotide (Figure 4A).

A completely different picture was observed in the hydrolysis of miR-137 by $11 \mathrm{IgG}$ preparations. All IgGs hydrolyzed miR-137 only specifically at five major sites: $3 \mathrm{~A}-4 \mathrm{U}>6 \mathrm{G}-7 \mathrm{C}$ $>11 \mathrm{~A}-12 \mathrm{G}>17 \mathrm{C}-18 \mathrm{G}>21 \mathrm{U}-22 \mathrm{~A}$ (Figure 4B). Only in the

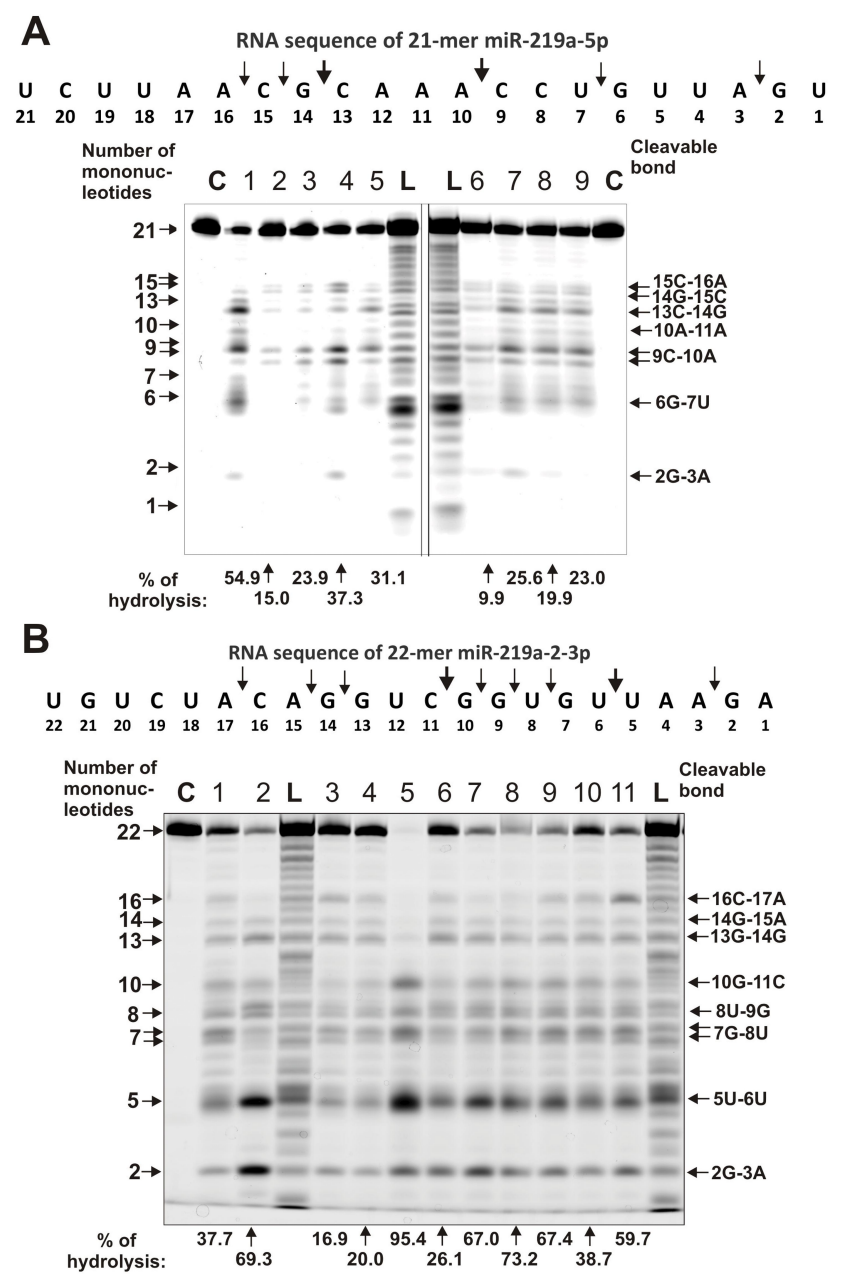

Figure 3 The patterns of Flu-miR-219-2-5p (A) and Flu-miR-219-2-3p (B) splitting by IgG preparations ( $0.6 \mu \mathrm{M}$ IgGs; I h of incubation) from sera of 9-1 I different SLE patients. The hydrolysis products were detected due to the fluorescent residue (Flu) on 5'-ends of the miRNAs. Lanes C correspond to miRNAs incubated without Abs, while lanes $L$ to oligonucleotide products length markers. The numbers of IgGs, lengths of the products, and the percentage of miRNAs hydrolysis by each IgG preparation are indicated on panels $(\mathbf{A}$ and $\mathbf{B})$.

case of this miRNA was observed effective cleavage of RNA in the region above 13 nucleotide link.

Several typical examples of four immunoregulatory miRNAs hydrolysis are given in Figures 5 and 6. Eleven IgG preparations showed a different combination of nonspecific and site-specific hydrolysis of miR-21-3p (Figure 5A). However, in all cases, three major specific sites of hydrolysis (6G-7U $>8 \mathrm{~A}-9 \mathrm{G} \geq 9 \mathrm{G}-10 \mathrm{U})$ and four medium ones $(5 \mathrm{~A}-6 \mathrm{C} \approx 13 \mathrm{~A}-14 \mathrm{U} \approx 2 \mathrm{~A}-3 \mathrm{~A})$ were revealed.

During the hydrolysis of miR-146a-3p (Figure 5B) with $\operatorname{IgG}$ preparations, in comparison with that for miR21-3p (Figure 5B), a more pronounced nonspecific cleavage of internucleoside phosphate bonds was observed. However, site-specific (12 C-13A and cluster of 5U-6G, 6G-7A, and 8A-9A sites) cleavage of four sites took place 

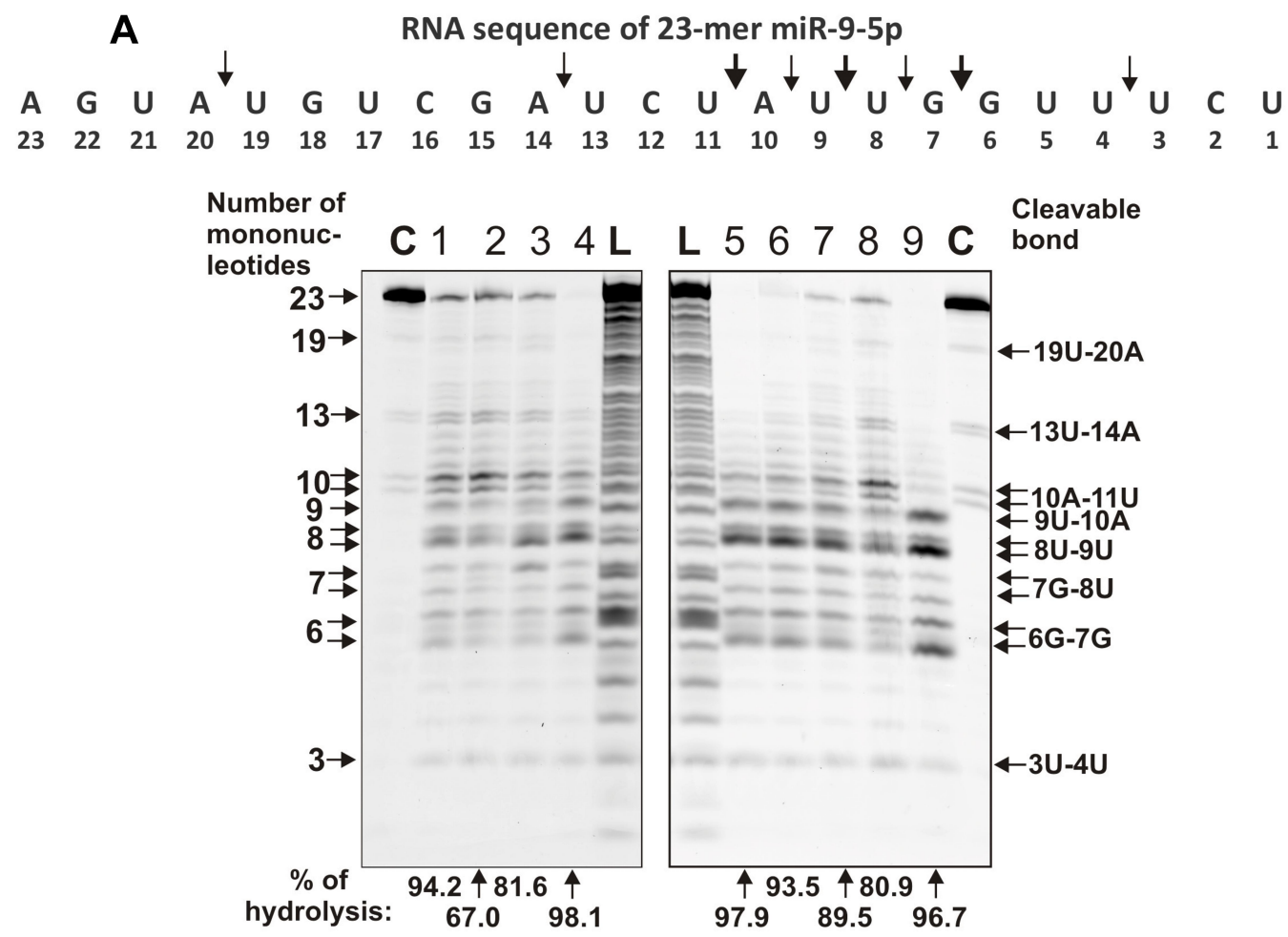

B
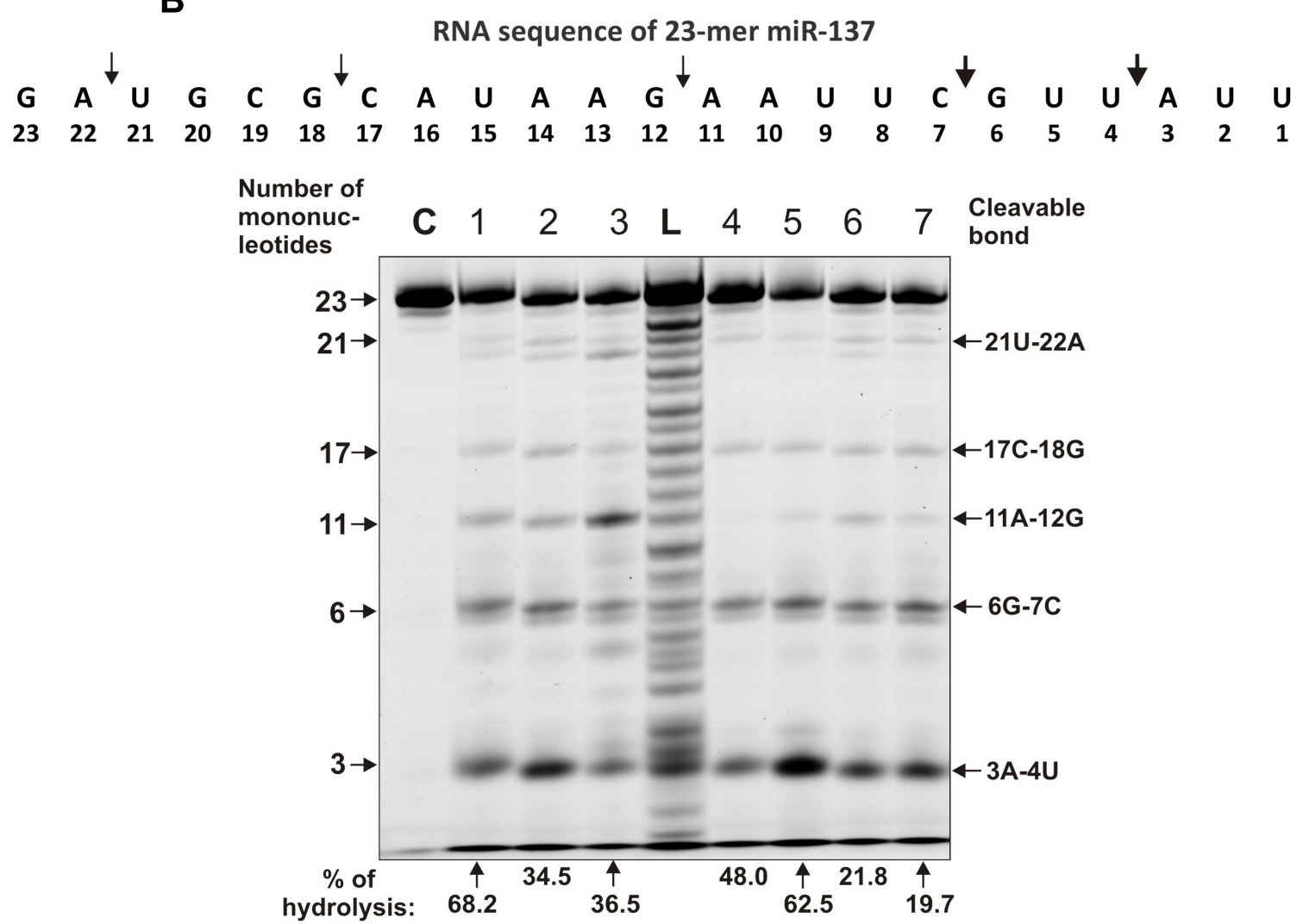

Figure 4 The patterns of Flu-miR-9-5p (A) and Flu- miR-I37 (B) hydrolysis by IgG preparations (0.6 $\mu$ M IgGs; I h of incubation) from sera of 7-9 different SLE patients. The hydrolysis products were detected due to the fluorescent residue (Flu) on 5'-ends of the RNAs. Lanes C correspond to miRNAs incubated without Abs, while lanes $L$ to oligonucleotide length markers. The numbers of $\operatorname{lgGs}$, lengths of the products, and the percentage of miRNAs hydrolysis by each preparation are indicated on panels (A and $\mathbf{B})$. 


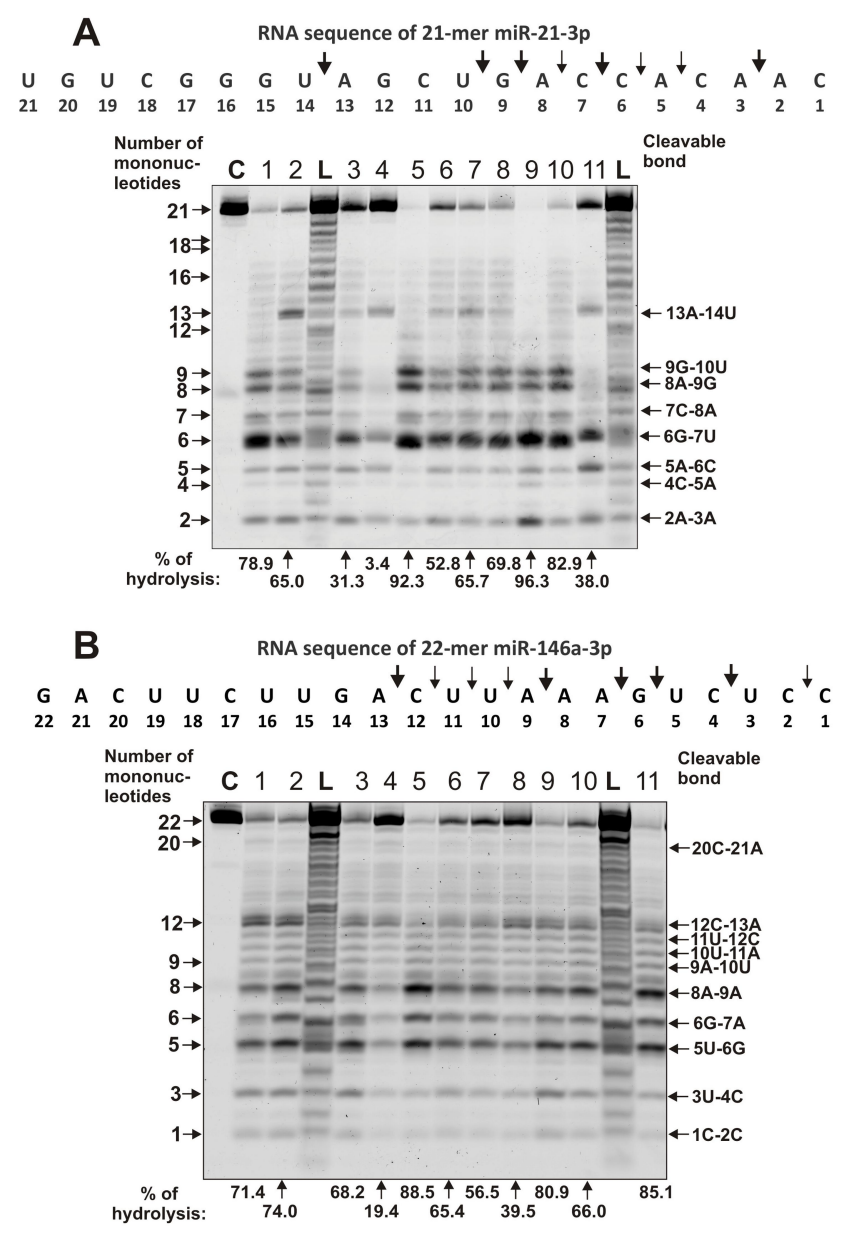

Figure 5 The patterns of Flu-miR-2I-3p (A) and Flu-miR-I46a-3p (B) hydrolysis by IgG preparations $(0.6 \mu \mathrm{M}$ IgGs; I h of incubation) from sera of II different SLE patients. The hydrolysis products were detected due to the fluorescent residue (Flu) on 5'-ends of the miRNAs. Lanes C correspond to miRNAs incubated without Abs, while lanes $L$ to oligonucleotide length markers. The numbers of $I g G s$, lengths of the products, and the percentage of miRNAs hydrolysis by each preparation are indicated on panels (A and $\mathbf{B})$.

in parallel with the perceptible non-specific splitting of miR-146a-3p. In addition, there was splitting of all bonds between 13A and 9A bases with a comparable efficiency. The minimal hydrolysis product was mononucleotide.

The cleavage of miR-155-5p by all eleven IgGs occurred mainly in four major sites: 5U-6G, 8U-9A, $11 \mathrm{U}-12 \mathrm{C}$, and 2U-3A (Figure 6A). However, in this case, there were many sites of medium and weak hydrolysis along almost the entire length of miRNA.

On the contrary, all IgGs efficiently hydrolyzed miR326 predominately site-specific in major $8 \mathrm{G}-9 \mathrm{C}$, 5U-6G, $8 \mathrm{G}-7 \mathrm{G}$ and medium 18C-19A, !2C-15C, and 13U-14C cleavage sites (Figure 6B).

Thus, depending on miRNA, there may be a combination of nonspecific and site-specific splitting, or occurs predominant specific hydrolysis. The ratio of nonspecific and site-specific hydrolysis to some extent depends on miRNA and the preparation of IgG. Some individual preparations from the blood of patients with SLE demonstrate almost only site-specific hydrolysis of several miRNAs.

\section{Comparison of Relative Activities of RNAs Hydrolysis}

The RAs in the hydrolysis of miRNAs by 11 MS IgGs were significantly different. However, all 11 preparations had relatively high ribonuclease activity in the hydrolysis of all miRNAs. For control, we used 14 preparations from the blood of conditionally healthy donors. Some of them demonstrated very weak, but reliably detectable RNase activity (see below). The RAs in the hydrolysis of riboONs and eight miRNAs by IgGs of SLE patients and conditionally healthy volunteers were estimated and normalized to standard conditions. All parameters were evaluated not only as average values \pm S.D., but also the medians (M) and interquartile ranges (IQR) were calculated (Tables 1 and 2). The maximum average RA was observed for miR-9-5p, while the minimum value in the case of miR-137; the difference is 2.6-fold (Table 1). In overall, the average RA values decreased in the following order: miR-9-5p, miR-155-5p, miR-326, miR-146a-3p, miR-21-3p, miR-219-2-3p, miR-137, and miR-219a-5p (Table 1). The average RAs for all eight miRNAs were estimated to be $62.9 \pm 27.3 \%$, while the median $=67.8$ and interquartile ranges $(\mathrm{IQR})=46.9 \%$.

Three of the 14 IgGs of conditionally healthy donors did not show a reliably tested RNase activity in the hydrolysis of any of eight miRNAs (Table 2). The remaining eleven IgGs nevertheless showed weak or very weak, but reliably detectable activity in the hydrolysis from three to eight different miRNAs (Table 2). Interestingly, all individual IgG preparations of healthy donors possessing ribonuclease activity hydrolyzed different miRNAs (Table 2).

The average RA for all eight miRNAs for healthy donors IgGs was estimated to be $2.3 \pm 2.3 \%$, while the median $=0.8$ and interquartile ranges $(\mathrm{IQR})=4.4$ (Table 2 ). Thus, the average activity of eight miRNA hydrolysis by IgGs of patients with SLE according to average and median values is approximately $27.3-84.8$-fold higher than that of healthy donors.

According to the Kruskal-Wallis test, the difference in relative RAs of eight miRNAs hydrolysis is statistically significant $(P<0.05)$ for 13 pairs of the RA sets, but not 
A

RNA sequence of 23-mer miR-155-5p

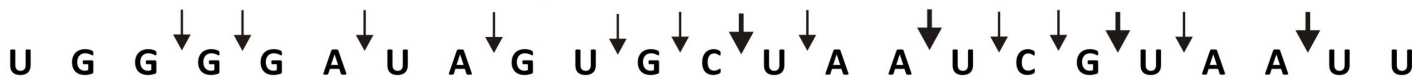

$\begin{array}{lllllllllllllllllllllll}23 & 22 & 21 & 20 & 19 & 18 & 17 & 16 & 15 & 14 & 13 & 12 & 11 & 10 & 9 & 8 & 7 & 6 & 5 & 4 & 3 & 2 & 1\end{array}$

Number of mononucleotides

Cleavable

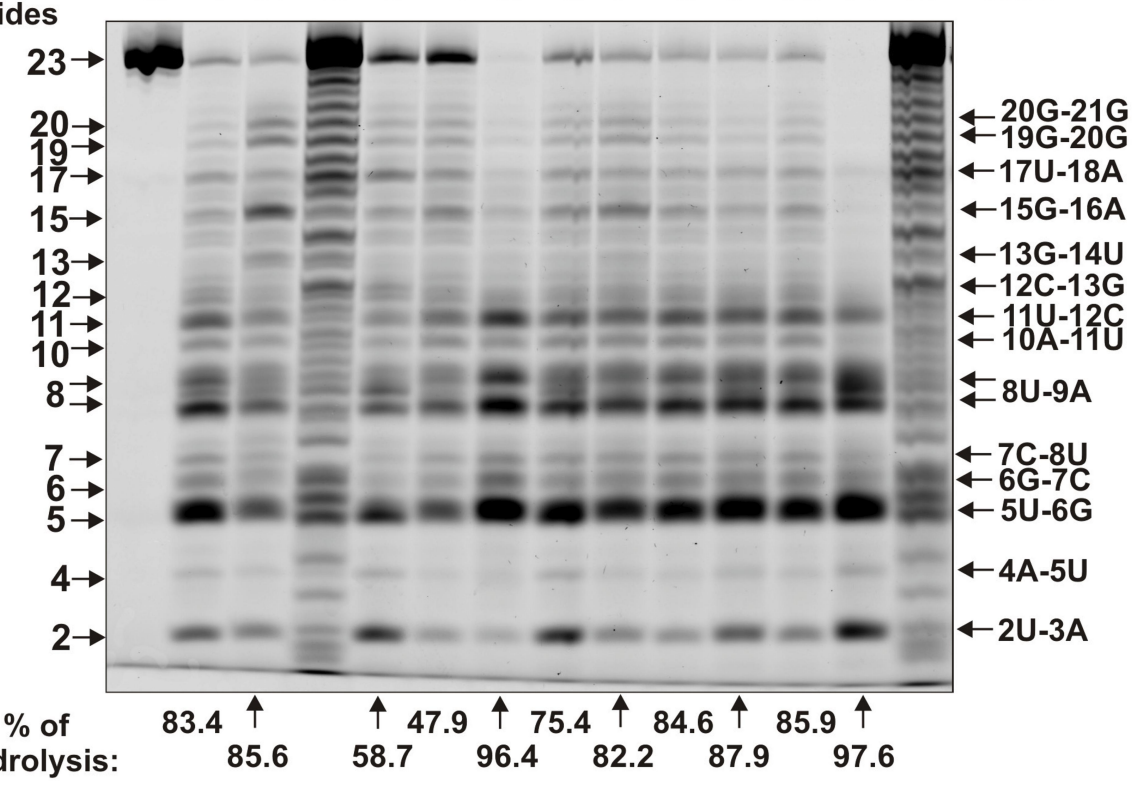

B

RNA sequence of 20-mer miR-326

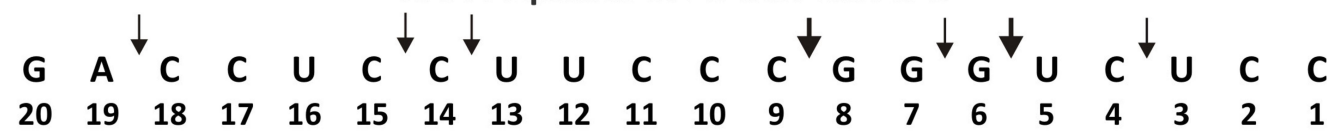

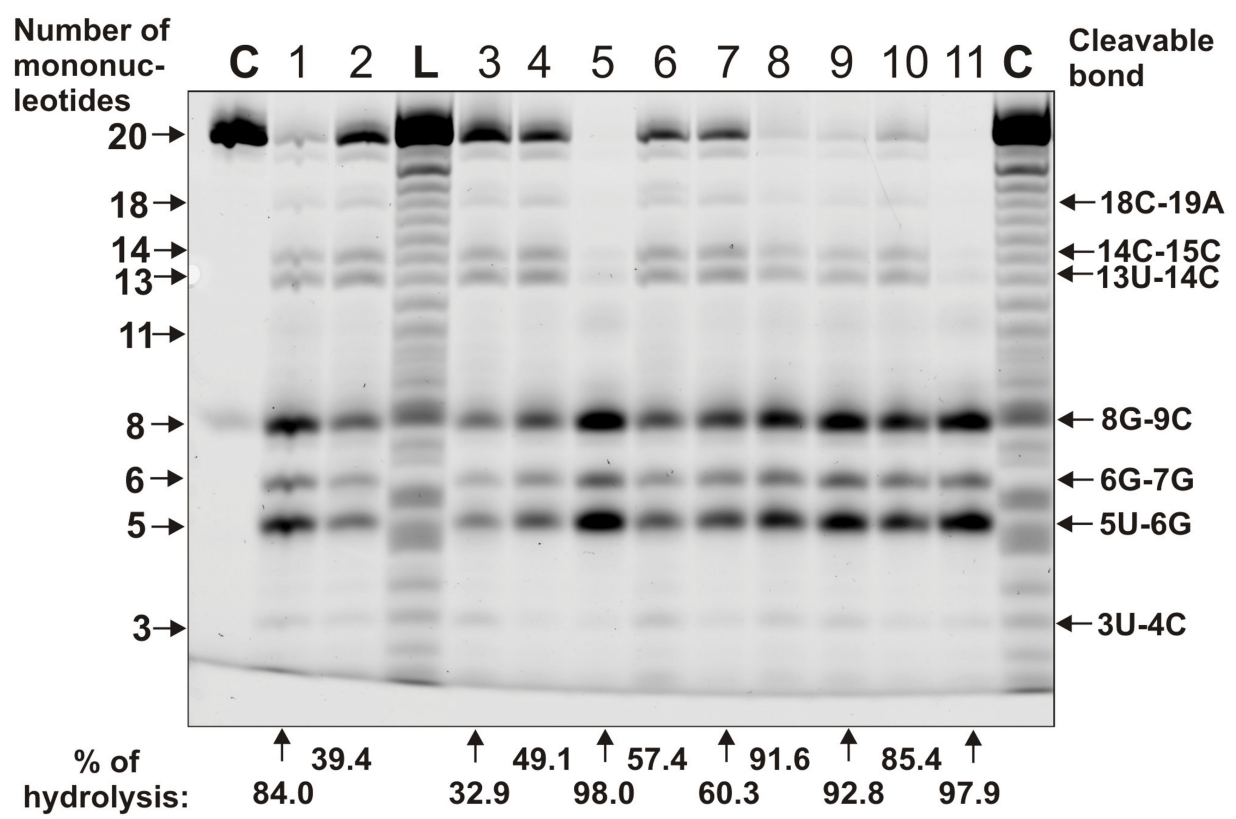

Figure 6 The patterns of Flu-miR-I55-5p (A) and Flu- miR-326 (B) hydrolysis by lgG preparations (0.6 $\mu$ M lgGs; I h of incubation) from sera of II different SLE patients. The hydrolysis products were detected due to the fluorescent residue (Flu) on $5^{\prime}$-ends of the miRNAs. Lanes $C$ correspond to miRNAs incubated without Abs, while lanes $L$ to oligonucleotide length markers. The numbers of $\operatorname{lgGs}$, lengths of the products, and the percentage of miRNAs hydrolysis by each preparation are indicated on panels (A and $\mathbf{B})$. 
reliable $(P>0.05)$ for 15 other RA pairs analyzed (Table 1$)$. Correlation coefficients (CCs) were also calculated for RA sets corresponding to eight miRNAs. All 25 correlation coefficients were positive and ranged from +0.14 to +0.84 (Table 1). For miR-137 weak negative correlations were observed with miR-9-5p (-0.12), miR-155-5p (-0.09), and miR-326 (-0.24) (Table 1).

In this article, spatial structures of miR-21-3p, miR146a-3p, miR-155-5p, and miR-326 possessing minimal free energy were calculated as in. ${ }^{28,29}$ Based on the data of 3 independent experiments for $11 \mathrm{IgG}$ preparations, the average efficiencies of the hydrolysis (\%) in all sites of these miRNAs were calculated. The hydrolysis efficiencies
(\%) at the major and moderate cleavage sites are shown in Figure 7. An interesting feature of the hydrolysis of all four miRNAs is that cleavage sites are located predominately in the duplex zones of these RNAs and to a lesser extent in their hairpin structures. In addition, some splitting sites correspond to 5 '-terminal fragments of these miRNAs, which are not involved in the formation of duplexes.

Spatial structures of four miRNAs (miR-219-2-3p, miR219a-5p, and miR-137) and efficiency of their hydrolysis in specific sites by SCZ IgGs were found earlier. ${ }^{28,29}$ Therefore, it was interesting to compare the similarity or difference in the hydrolysis of these four miRNAs with antibodies from

Table I Relative Hydrolysis of Eight Different miRNAs by Polyclonal IgGs from the Sera of SLE Patients

\begin{tabular}{|c|c|c|c|c|c|c|c|c|}
\hline \multirow{2}{*}{$\begin{array}{l}\text { Numbers of Patient and Corresponding } \\
\text { lgG Preparations }\end{array}$} & \multicolumn{8}{|c|}{ miRNA-Hydrolyzing Activity of IgG, \%* } \\
\hline & $\begin{array}{l}\text { miR- } \\
137 \\
(1)\end{array}$ & $\begin{array}{l}\text { miR- } \\
9-5 p \\
(2)\end{array}$ & $\begin{array}{l}\text { miR-219- } \\
2-3 p(3)\end{array}$ & $\begin{array}{l}\text { miR-2 I9a- } \\
5 p(4)\end{array}$ & $\begin{array}{l}\text { miR- } \\
21-3 p \\
(5)\end{array}$ & $\begin{array}{l}\text { miR-146a- } \\
3 p(6)\end{array}$ & $\begin{array}{l}\text { miR-I55- } \\
5 p(7)\end{array}$ & $\begin{array}{l}\text { miR- } \\
326 \\
(8)\end{array}$ \\
\hline \multicolumn{9}{|l|}{ SLE patients } \\
\hline 1 & $72.4^{*}$ & 98.1 & 37.7 & 31.1 & 78.9 & 71.4 & 83.4 & 84.0 \\
\hline 2 & 76.3 & 81.6 & 69.3 & 37.3 & 65.0 & 74.0 & 85.6 & 39.4 \\
\hline 3 & 62.5 & 67.0 & 16.9 & 23.9 & 31.3 & 68.2 & 58.7 & 32.9 \\
\hline 4 & 48.0 & 72.7 & 20.0 & 15.0 & 3.4 & 19.4 & 47.9 & 49.1 \\
\hline 5 & 93.7 & 96.7 & 95.4 & 54.9 & 92.3 & 88.5 & 96.4 & 98.0 \\
\hline 6 & 34.5 & 80.9 & 26.1 & 9.9 & 52.8 & 65.4 & 75.4 & 57.4 \\
\hline 7 & 68.2 & 89.5 & 67.0 & 25.6 & 65.7 & 56.5 & 82.2 & 60.3 \\
\hline 8 & 10.3 & 93.5 & 73.2 & 19.9 & 69.8 & 39.5 & 84.6 & 91.6 \\
\hline 9 & 36.5 & 97.9 & 67.4 & 23.0 & 96.3 & 80.9 & 87.9 & 92.8 \\
\hline 10 & 21.8 & 94.0 & 38.7 & 40.3 & 82.9 & 66.0 & 85.9 & 85.4 \\
\hline 11 & 19.7 & 99.8 & 59.7 & 97.2 & 38.0 & 85.1 & 97.6 & 97.9 \\
\hline Mean \pm SD for individual RNAs & $\begin{array}{l}49.4 \pm \\
27.0\end{array}$ & $\begin{array}{l}88.3 \pm \\
11.2\end{array}$ & $51.9 \pm 25.4$ & $34.4 \pm 24.3$ & $\begin{array}{l}61.5 \pm \\
28.2\end{array}$ & $65.0 \pm 20.4$ & $80.5 \pm 15.0$ & $\begin{array}{l}71.7 \pm \\
24.4\end{array}$ \\
\hline Median (IQR) for individual RNAs** & $\begin{array}{l}48.0 \\
(42.2)\end{array}$ & $\begin{array}{l}93.5 \\
(16.1)\end{array}$ & $59.7(36.5)$ & $25.6(17.4)$ & $\begin{array}{l}65.7 \\
(35.5)\end{array}$ & $68.2(16.5)$ & $84.6(8.1)$ & $\begin{array}{l}84.0 \\
(39.0)\end{array}$ \\
\hline Order of increase in RAs & 7 & $\mathbf{I}$ & 6 & 8 & 5 & 4 & 2 & 3 \\
\hline Average value for all 8 microRNAs & \multicolumn{8}{|c|}{$62.9 \pm 27.3$} \\
\hline M (IQR) for all 8 microRNAs & \multicolumn{8}{|c|}{$67.8(46.9)$} \\
\hline Difference between sets, $P$ & \multicolumn{8}{|c|}{$\begin{array}{l}\text { I-2 (0.00I)***, I-3 (0.84), I-4 (0.24), I-5 (0.29), I-6 (0.2), I-7 (0.07), I-8 (0.076), 2-3 (0.00I), 2-4 } \\
(0.006), 2-5(0.007), 2-6(0.003), 2-7(0.02), 2-8(0.1), 3-4(0.09), 3-5(0.39), 3-6(0.21), 3-7(0.007), \\
3-8(0.1), 4-5(0.03), 4-6(0.01), 4-7(0.001), 4-8(0.003), 5-6(0.79), 5-7(0.07), 5-8(0.36), 6-7 \\
(0.04), 6-8(0.43) \text {, and 7-8 (0.74) }\end{array}$} \\
\hline Correlation coefficients & \multicolumn{8}{|c|}{$\begin{array}{l}\text { I-2 (-0.12), I-3 (+014), I-4 (+0.26), I-5 (+0.14), I-6 (+0.35), I-7 (-0.09), I-8 (-0.24), 2-3 (+0.46), 2-4 } \\
(+0.6), 2-5(+0.61), 2-6(+0.61), 2-7(+0.81), 2-8(+0.84), 3-4(+0.37), 3-5(+0.64), 3-6(+0.39), 3-7 \\
(+0.69), 3-8(+0.62), 4-5(+0.28), 4-6(+0.71), 4-7(+0.74), 4-8(+0.46), 5-6(+0.41), 5-7(+0.6), 5-8 \\
(+0.65), 6-7(+0.77), 6-8(+0.5), \text { and } 7-8(0.82)\end{array}$} \\
\hline
\end{tabular}

Notes: *For each value, a mean of three measurements is reported; the error of the determination of values did not exceed $7-10 \%$. ${ }^{*}$ The median (M) and interquartile ranges (IQR). ***bold indicate $\mathrm{P}<0.05$ 
Table 2 Relative Hydrolysis of Eight Different miRNAs by Polyclonal IgGs from the Sera of I4 Conditionally Healthy Donors

\begin{tabular}{|c|c|c|c|c|c|c|c|c|}
\hline \multirow{2}{*}{$\begin{array}{l}\text { Numbers of Patient and Corresponding } \\
\text { lgG Preparations }\end{array}$} & \multicolumn{8}{|c|}{ miRNA-Hydrolyzing Activity of IgG, \%* } \\
\hline & $\begin{array}{l}\text { miR- } \\
137 \\
\text { (1) }\end{array}$ & $\begin{array}{l}\text { miR- } \\
9-5 p \\
(2)\end{array}$ & $\begin{array}{l}\operatorname{miR}-219- \\
2-3 p(3)\end{array}$ & $\begin{array}{l}\text { miR-219a- } \\
5 p(4)\end{array}$ & $\begin{array}{l}\text { miR- } \\
2 \mid-3 p \\
(5)\end{array}$ & $\begin{array}{l}\text { miR-1 46a- } \\
3 p(6)\end{array}$ & $\begin{array}{l}\text { miR-I55- } \\
5 p(7)\end{array}$ & $\begin{array}{l}\text { miR- } \\
326 \\
(8)\end{array}$ \\
\hline \multicolumn{9}{|l|}{ Healthy donors } \\
\hline 1 & 7.8 & 6.4 & 0 & 0 & 7.3 & 8.8 & 9.4 & 0 \\
\hline 2 & 0 & 2.9 & 5.2 & 2.7 & 0 & 0 & 3.1 & 3.4 \\
\hline 3 & 4.4 & 5.7 & 0 & 0 & 5.1 & 4.5 & 3.8 & 0 \\
\hline 4 & 0 & 3.6 & 5.1 & 4.3 & 0 & 5.8 & 7.2 & 0 \\
\hline 5 & 2.2 & 4.8 & 5.7 & 3 & 3.3 & 4.4 & 0 & 4.6 \\
\hline 6 & 0 & 5.5 & 2.7 & 3.8 & 7.1 & 4.2 & 3.1 & 0 \\
\hline 7 & 0.7 & 8.2 & 4.6 & 3.8 & 5.4 & 5.5 & 9.7 & 4.3 \\
\hline 8 & 1.3 & 6.9 & 0.3 & 3.3 & 6.4 & 4.2 & 2.8 & 2.7 \\
\hline 9 & 0 & 5.2 & 0 & 0.8 & I.I & 0.7 & 6.5 & 0 \\
\hline 10 & 0 & 3.2 & 0 & 0 & 0 & 0.8 & 4.7 & 0 \\
\hline 11 & 0 & 2.1 & 0 & 0 & 0.9 & 0.4 & 4.2 & 0 \\
\hline 12 & 0 & 0 & 0 & 0 & 0 & 0 & 0 & 0 \\
\hline 13 & 0 & 0 & 0 & 0 & 0 & 0 & 0 & 0 \\
\hline 14 & 0 & 0 & 0 & 0 & 0 & 0 & 0 & 0 \\
\hline Mean \pm SD for individual RNAs & $\begin{array}{l}1.2 \pm \\
2.3\end{array}$ & $\begin{array}{l}3.9 \pm \\
2.7\end{array}$ & $1.7 \pm 2.7$ & $1.6 \pm 2.4$ & $\begin{array}{l}1.5 \pm \\
1.8\end{array}$ & $2.6 \pm 3.0$ & $2.8 \pm 2.9$ & $\begin{array}{l}3.9 \pm \\
3.3\end{array}$ \\
\hline Median (IQR) for individual RNAs** & $\begin{array}{l}0 \\
(2.3)\end{array}$ & $\begin{array}{l}4.2 \\
(3.6)\end{array}$ & $0(4.6)$ & $0.4(3.3)$ & $\begin{array}{l}1.0 \\
(3.0)\end{array}$ & $2.5(4.5)$ & $3.4(6.5)$ & $\begin{array}{l}0 \\
(2.7)\end{array}$ \\
\hline Order of increase in RAs & 8 & 1 & 5 & 6 & 7 & 4 & 3 & 2 \\
\hline Average value for all microRNAs & \multicolumn{8}{|c|}{$2.3 \pm 2.7$} \\
\hline M (IQR) for all microRNAs & \multicolumn{8}{|c|}{$0.8(4.4)$} \\
\hline Spearman's corr. coefficient & \multicolumn{8}{|c|}{ The correlation coefficient $(\mathrm{R})$ varied from 0.11 to 0.85 . } \\
\hline
\end{tabular}

Notes: *For each value, a mean of three measurements is reported; the error of the determination of values did not exceed $7-10 \%$. $* *$ The median (M) and interquartile ranges (IQR)

the sera of SCZ and SLE patients. Figure 8 demonstrates positions and average RAs (\%) of miR-219-2-3p and miR219a-5p hydrolysis by SCZ and SLE IgGs. The main cleavage sites of miR-219-2-3p in the case of SCZ and SLE IgGs are located in the duplex part and the adjacent hairpin structure of 5-terminal half of miRNA. In overall, six of cleavage sites are the same. However, there are several specific sites of miR-219a-5p hydrolysis by SCZ IgGs (6U-7G, 9G-10G, 11C-12U, 14G-15A) as well as by SLE abzymes (3F-4A, 14G-15A) (Figure 8A).

SCZ abzymes split miR-219a-5p at nine, while SLE IgGs only at seven sites; five of them coincide, and the rest are different (Figure 8B). The most characteristic difference is the efficient hydrolysis of this miRNA by SLE IgGs at $2 \mathrm{G}-3 \mathrm{~A}$ site.

In the case of hydrolysis of miR-9-5p by antibodies of SLE and SCZ patients, eight major and average cleavage sites are observed, of which coincide only five (Figure 9A).
Three sites of cleavage of this miRNA by abzymes of patients with SCZ (11U-12C, 12C-13U, and 13U-14A) differ from those for patients with SLE. One specific major site of miR-9-5p cleavage with SLE IgGs is located in the duplex part (7G-8U) and two average ones in the 5'-(3U-4U) and 3'terminal (19U-20A) zones of miRNA (Figure 9A).

Only one (6G-7C) cleavage site of miR-137 is common for SCZ and SLE IgGs (Figure 9B). In contrast to SLE abzymes, SCZ IgGs hydrolyze this miRNA at the following sites: 5U-6G, 8U-9U, 9U-10A, 10A-11A, 13A-14A, $14 \mathrm{U}-16 \mathrm{~A}$. In the case of Abs of SLE patients, there are also specific sites of the hydrolysis: $3 \mathrm{~A}-4 \mathrm{U}, 11 \mathrm{~A}-12 \mathrm{G}$, $17 \mathrm{C}-18 \mathrm{G}$, and $21 \mathrm{U}-22 \mathrm{~A}$.

The Kruskal-Wallis one-way analysis of variance (ANOVA) was used to assess the significance of differences between average values of microRNA hydrolysis levels $(\%)$ at the major sites of microRNAs by antibodies 

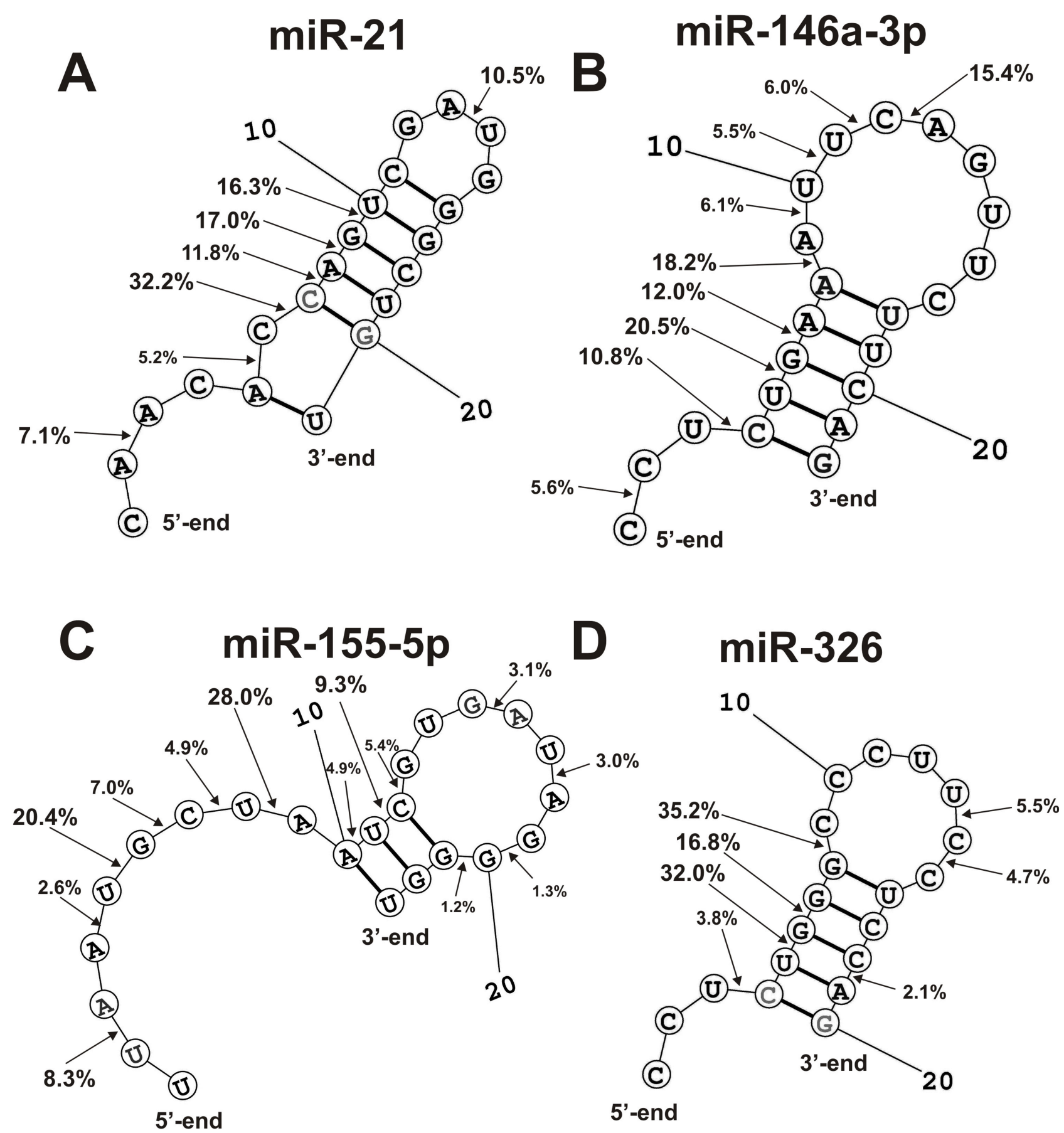

Figure 7 The average efficiency (\%) of Flu-miR-2I (A) and Flu- miR-146A-3p (B), Flu- miR-155-5p (C) and miR-326 (D) hydrolysis by eleven SLE IgGs (A-D) in all major and medium sites of their cleavage. The average percentage and position of major and moderate sites of miRNAs hydrolysis by lgGs are shown on the panels.

of schizophrenic $(\mathrm{n}=21)$ and $\operatorname{SLE}(\mathrm{n}=11)$ patients (Figures 8 and 9). It was shown that the hydrolysis levels at the main sites of microRNAs hydrolysis were statistically significantly different $(P<0.05)$ in schizophrenia and SLE pathologies.

Thus, on the whole, there may be significant differences in the hydrolysis of four miRNAs by abzymes from the blood of patients with SLE and SCZ. However, the level of these differences depends on the specific miRNA analyzed.

\section{Discussion}

It was shown recently that IgGs of schizophrenia patients effectively hydrolyze four miRNAs: miR-137, miR-9-5p, 


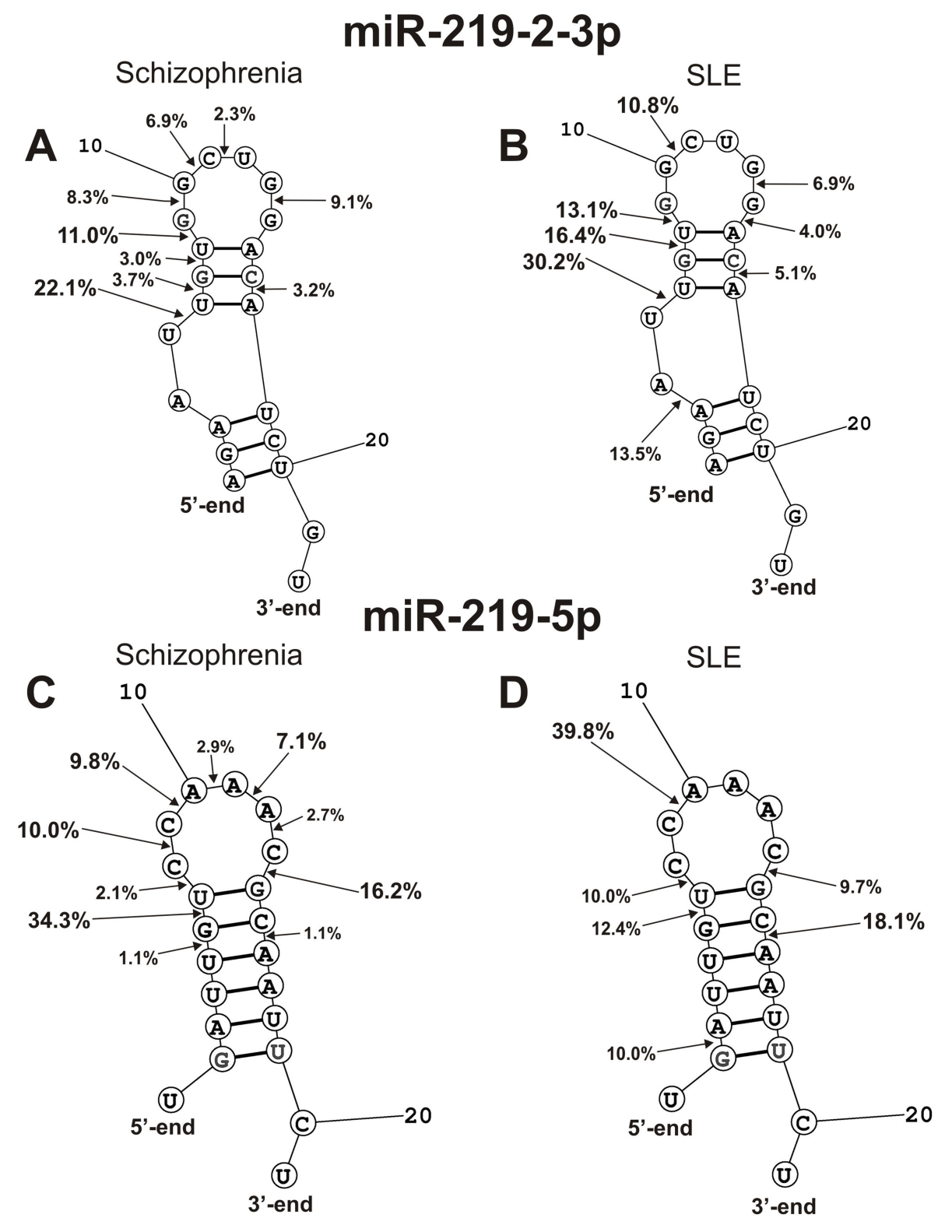

Figure 8 The average efficiency of Flu- miR-219-2-3p (A and B) and Flu-miR-219a-5p (C and D) splitting by SCZ IgGs (A and C) and SLE IgGs (B and D) in all major and medium sites of their cleavage. The average percentage and position of major and moderate sites of miRNAs hydrolysis by lgGs are shown on the panels. For comparison, the data on the hydrolysis of miRNAs IgGs of schizophrenia patients are taken from previously published articles. ${ }^{29,30}$

miR-219-2-3p, and miR-219a-5p. ${ }^{28,29}$ Abzymes of SLE patients hydrolyze MBP, DNA, histones, and oligosaccharides. ${ }^{9-14}$ In addition, all 11 SLE IgGs effectively hydrolyze three ribo-ONs (Figure 2B) and eight different miRNAs (Figures 3-6, Table 1). The hydrolysis of all three ribo-ONs proceeded non-specifically (Figure 2B). Splitting of eight miRNAs in the contrast was predominately site-specific (Figures 3-6). Nevertheless, several individual IgGs from sera of several SLE patients hydrolyzed some miRNAs demonstrating a combination of non-specific and site-specific splitting.
Interestingly, the highest and comparable levels of miRNA-hydrolyzing activity of SLE IgGs were detected for neuroregulatory miR-9-5p, as well as proinflammatory miR-155-5p and miR-326, for which the increase of their expression in the blood of patients with SLE was found. ${ }^{42,53-55}$ MiR-9-5p plays an important role in the development of lupus nephritis. ${ }^{56}$ MiR-326 activates the production of Abs in B cells in autoimmune MRL/lpr mice. $^{57}$ In addition, miR-99-5p stimulates the production of the pro-inflammatory cytokine IL-2 in CD4 $\mathrm{T}$ cells. The decrease in these miRNAs 


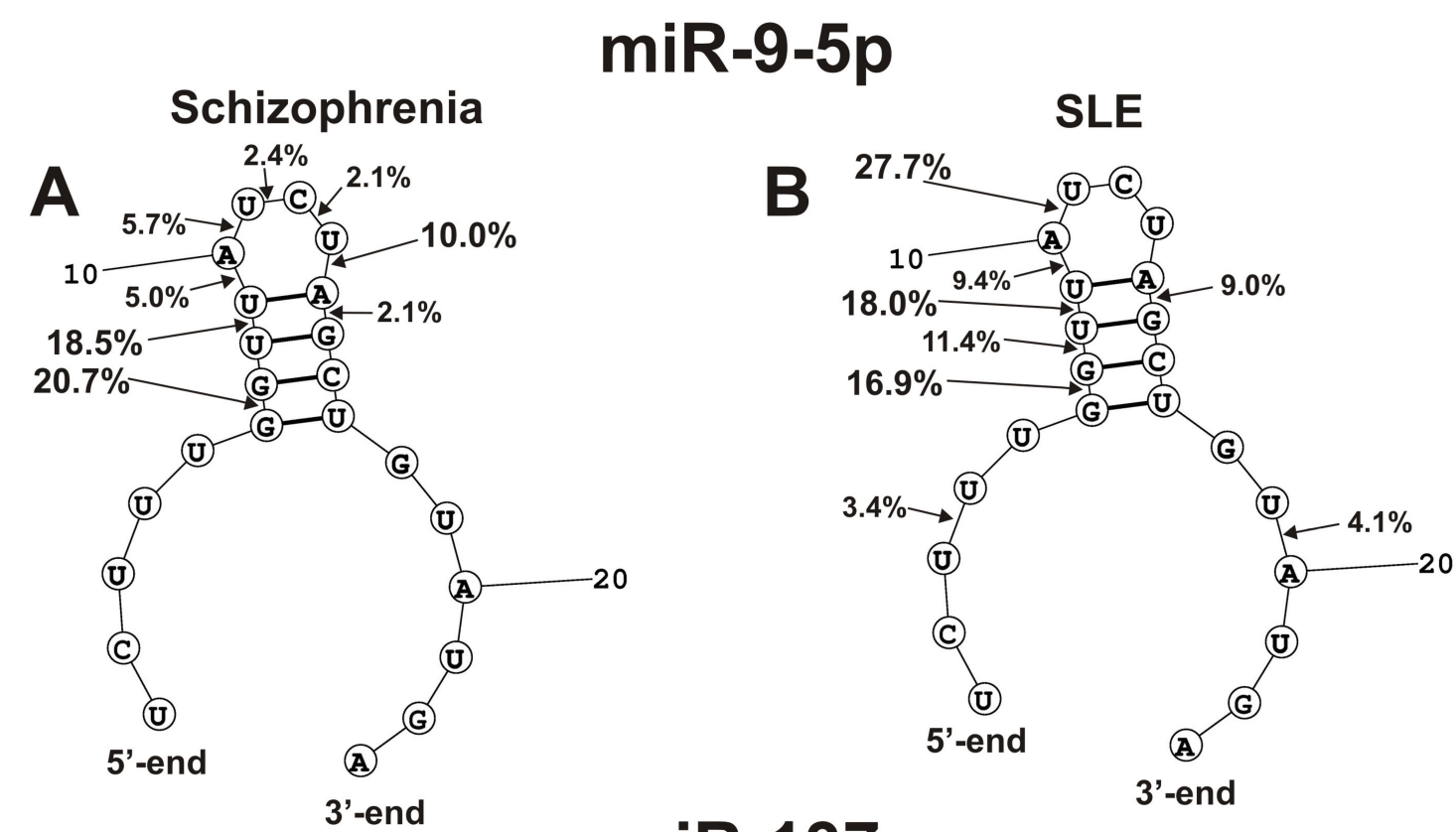

\section{$\operatorname{miR}-137$}
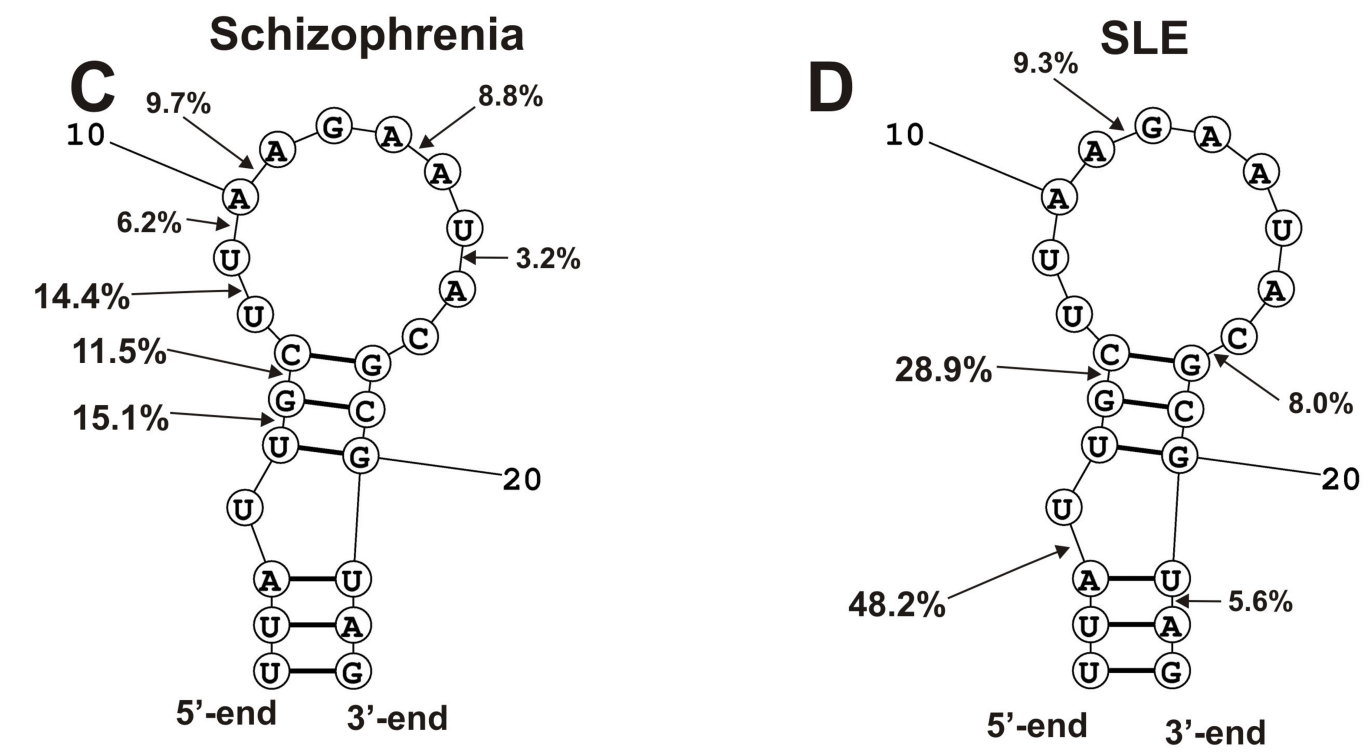

Figure 9 The average efficiency of Flu- mir-9-5p (A and B) and Flu-miR-I37 (C and D) splitting by eleven SCZ IgGs (A and C) and SLE IgGs (B and D) in all major and medium sites of their cleavage. The average percentage and position of major and moderate sites of miRNAs hydrolysis by lgGs are shown on the panels. For comparison, the data on the hydrolysis of miRNAs IgGs of schizophrenia patients are taken from previously published articles. ${ }^{29,30}$

concentrations due to their hydrolysis with blood abzymes can lead to a decrease in the efficiency of their functioning in patients with SLE.

As indicated above, in early studies ${ }^{38,39}$ it was shown that IgGs of healthy donors, with very few exceptions, do not hydrolyze RNA. It should be assumed that at present the blood of conditionally healthy donors may still contain abzymes that hydrolyze RNA. Eleven of 14 conditionally healthy donors IgGs demonstrate low, but detectable
RNase activity (Table 2). Nevertheless, the average RNase activity of 14 IgG preparations was $27.3-84$.8-fold lower than that for eleven SLE patients.

Interestingly, the average efficiency of hydrolysis of four miRNAs (miR-137, miR-9-5p, miR-219-2-3p, miR219a-5p) with $21 \mathrm{SCZ}$ Abs (average value $61.6 \pm 32.7$, $\mathrm{M}=62.9, \mathrm{IQR}=60.6)^{28,29}$ and 11 patients with SLE was only slightly different (average value $56.2 \pm 29.8 .8, \mathrm{M}=$ 61.1.8, IQR = 26.0). 
On the whole, the number of major and moderate sites of the hydrolysis was individual for each of miRNA and IgG preparation (Figures 3-6). In the case of the hydrolysis of eight miRNAs by SLE and SCZ abzymes, specific cleavage sites are located mainly in their duplex zones and to a lesser extent in their hairpin structures (Figures 7-9). Nevertheless, in contrast to SCZ antibodies, SLE abzymes are characterized by miRNAs splitting sites located in the 5'-terminal part of RNAs (Figures 7-9). For some miRNAs, there are not very large differences in their hydrolysis with SCZ and SLE antibodies; the maximum difference was found in the splitting of miR-137. Very similar patterns corresponding to the formation of three major and four average products were observed for all eleven SLE IgGs in the case of miR-137 (Figure 6B). It was shown earlier that hydrolysis of miR-137 by SCZ IgGs also proceeds very specifically with the formation of three major and four average products of the hydrolysis. ${ }^{28,29}$ However, these products of hydrolysis of miR-137 by IgGs of SLE and SCZ patients turned out to be, with the exception of one, completely different (Figure 9B).

The CCs of RA sets corresponding to eight miRNAs splitting were very different and varied from positive $(+0.14-+0.84)$ to negative $(-0.09--0.24)$ (Table 1$)$. The reason for this may be that in the case of each individual SLE patient, auto-Abs and abzymes against various miRNAs can produce with different efficiencies.

We hypothesize that catalytic antibodies can degrade both highly expressed and low-expressed miRNAs, leading to dysregulation of microRNAs. Enhanced recognition of a specific microRNA can lead to a decrease in its expression. At the same time, it can be proposed that the formation of abzymes that hydrolyze highly expressed miRNAs may be a compensatory reaction against these microRNAs. Thus, catalytic antibodies can probably play both a negative and a compensatory role in SLE. Although miRNAs are predominantly localized in the cell, many stable miRNAs circulate in the extracellular space. ${ }^{25}$ The release of microRNA from the cell is possible due to a passive pathway, due to apoptosis or necrosis, or active secretion using vesicles, exosomes, and complexes with proteins or lipoproteins. ${ }^{25}$ Importantly, some singlestranded RNAs (ssRNA), including miRNAs, activate RNA-sensing Toll-like receptor 7 (TLR7), leading to activation of inflammation and neurodegeneration. ${ }^{58}$ However, RNA-sensing TLR7 and TLR8 are located in endolysosomes. ${ }^{59}$ TLR7 and TLR8 are activated by the
RNA degradation products, which generate endosomal RNase T2 and RNase 2. ${ }^{59,60}$ There is ample evidence that $\mathrm{IgG}$ immune complexes are transported through $\mathrm{Fc}$ receptors into lysosomes. ${ }^{61-63}$ Therefore, it can be assumed that catalytic antibodies that hydrolyze RNA and miRNAs, along with RNase T2 and RNase 2, are involved in the activation of TLR7 and TLR8. Moreover, it is known that some antibodies can enter the cell through interaction with receptors or antigens. ${ }^{64}$ In addition, a sequence-specific, nucleotide-hydrolyzing, cell-penetrating antibody 3D8 was developed, which was used to reduce the mRNA level of the target gene Her $2{ }^{65}$ Thus, some RNA-hydrolyzing antibodies can enter the cell and lead to dysregulation of miRNAs expression.

It was previously shown that with Abs and SLE patients efficiently hydrolyze DNA, RNA, MBP, and polysaccharides, ${ }^{10-14}$ while SCZ IgGs cleave DNA, MBP, and miRNas. ${ }^{28-32}$ Here, it was shown for the first time SLE IgGs efficient and site-specific hydrolyze eight miRNAs somewhat similar to the Abs of schizophrenic patients. It cannot be ruled out that autoimmune processes in patients with SLE and SCZ are more or less similar. In addition, some similar neuropsychiatric disorders were revealed for SCZ and $50 \%$ of SLE patients. ${ }^{34}$

\section{Conclusion}

In this work, we first showed that the blood of patients with SLE contains autoantibodies and abzymes against miRNAs efficiently and site-specific hydrolyzing these miRNAs. In addition, one cannot exclude that miRNA-, MBP-, and DNA-hydrolyzing abzymes in addition to other different factors may cooperatively promote important autoimmune and neuropathologic mechanisms in SLE and SCZ pathogenesis.

\section{Abbreviations}

Abs, antibodies; Abzs, abzymes or catalytic antibodies; AI, autoimmune; AIDs, autoimmune diseases; MS, multiple sclerosis; PAGE, polyacrylamide gel electrophoresis; RA, relative activity; SCZ, schizophrenia; SLE, systemic lupus erythematosus, SDS, sodium dodecyl sulfate.

\section{Acknowledgments}

We are very grateful for A. G. Venyaminova and M. I. Meschaninova for the synthesis of ribooligonucleotides. This research was maintained by the Russian Science Foundation (20-14-00162). A part of work corresponding to a collection of the blood of SLE patients and 
purification of some IgG preparations were supported by the grant of Russian Foundation for Basic Research (20015-00156)

\section{Disclosure}

The authors declare no conflicts of interest for this work.

\section{References}

1. Pisetsky D. Immune response to DNA in systemic lupus erythematosus. Isr Med Ass J. 2001;3:850-853.

2. Shoenfeld Y, Ben-Yehuda O, Messinger Y, et al. Autoimmune diseases other than lupus share common anti-DNA idiotypes. Immunol Lett. 1988;17:285-291. doi:10.1016/0165-2478(88)90043-0

3. Ikehara S, Kawamura M, Takao F. Organ-specific and systemic autoimmune diseases originate from defects in hematopoietic stem cells. Proc Natl Acad Sci USA. 1990;87:8341. doi:10.1073/ pnas.87.21.8341

4. Andryushkova AA, Kuznetsova IA, Orlovskaya IA, et al. Antibodies with amylase activity from the sera of autoimmune-prone MRL/ MpJ-1pr mice. FEBS Lett. 2006;580:5089-5095. doi:10.1016/j. febslet.2006.08.036

5. Andryushkova AA, Kuznetsova IA, Orlovskaya IA, et al. Nucleotidehydrolyzing antibodies from the sera of autoimmune-prone MRL-lpr/ lpr mice. Int Immunol. 2009;21:935-945. doi:10.1093/intimm/ dxp060

6. Andryushkova AA, Kuznetsova IA, Buneva VN, et al. Formation of different abzymes in autoimmune-prone MRL-lpr/lpr mice is associated with changes in colony formation of haematopoetic progenitors. J Cell Mol Med. 2007;11:531-551. doi:10.1111/j.15824934.2007.00048.x

7. Doronin VB, Parkhomenko TA, Korablev A, et al. Changes in different parameters, lymphocyte proliferation and hematopoietic progenitor colony formation in EAE mice treated with myelin oligodendrocyte glycoprotein. J Cell Mol Med. 2016;20:81-94. doi: $10.1111 / \mathrm{jcmm} .12704$

8. Aulova KS, Toporkova LB, Lopatnikova JA, et al. Changes in haematopoietic progenitor colony differentiation and proliferation and the production of different abzymes in EAE mice treated with DNA. J Cell Mol Med. 2017;21:3795-3809. doi:10.1111/jcmm.13289

9. Keinan E, Ed, Catalytic Antibodies. Weinheim, Germany: WileyVCH Verlag GmbH and Co. KgaA; 2005:1-586.

10. Nevinsky GA, Buneva VN. Natural catalytic antibodies-abzymes. In: Catalytic Antibodies. Keinan E, editor. Weinheim, Germany: VCHWiley Press; 2005:505-569.

11. Nevinsky GA, Natural catalytic antibodies in norm and in autoimmune diseases. In: Autoimmune Diseases: Symptoms, Diagnosis and Treatment. Brenner KJ, editor. New York, NY, USA: Nova Science Publishers Inc; 2010: 1-10. Nevinsky GA. Natural catalytic antibodies in norm and in HIV-infected patients. In Understanding HIV/AIDS Management and Care-Pandemic Approaches the 21st Century, Kasenga, FH, Ed., InTech: Rijeka, Croatia, 2011, pp. 151-192.

12. Nevinsky GA. Catalytic antibodies in norm and systemic lupus erythematosus. In: Lupus. Khan WA, editor. Rijeka, Croatia: InTech; 2017:41-101.

13. Nevinsky GA. Autoimmune processes in multiple sclerosis: production of harmful catalytic antibodies associated with significant changes in the hematopoietic stem cell differentiation and proliferation. In: Multiple Sclerosis. Conzalez-Quevedo A, editor. Rijeka, Croatia: InTech; 2016:100-147.

14. Kozyr AV, Kolesnikov AV, Aleksandrova ES, et al. Novel functional activities of anti-DNA autoantibodies from sera of patients with lymphoproliferative and autoimmune diseases. Appl Biochem Biotechnol. 1998;75:45-61. doi:10.1007/BF02787708
15. Nevinsky GA, Buneva VN. Catalytic antibodies in healthy humans and patients with autoimmune and viral pathologies. J Cell Mol Med. 2003;7:265-276. doi:10.1111/j.1582-4934.2003.tb00227.x

16. Founel S, Muller S. Antinucleosome antibodies and T-cell response in systemic lupus erythematosus. Ann Med Interne. 2002; 153:513-519.

17. Andrievskaya OA, Buneva VN, Naumov VA, Nevinsky GA. Catalytic heterogeneity of polyclonal RNA-hydrolyzing IgM from sera of patients with lupus erythematosus. Med Sci Monit. 2000;6:460-470.

18. Andrievskaya OA, Buneva VN, Baranovskii AG, et al. Catalytic diversity of polyclonal RNA-hydrolyzing IgG antibodies from the sera of patients with systemic lupus erythematosus. Immunol Lett. 2002;81:191-198. doi:10.1016/S0165-2478(02)00006-8

19. Lee RC, Feinbaum RL, Ambros V. The C. elegans heterochronic gene lin-4 encodes small RNAs with antisense complementarity to lin-14. Cell. 1993;75:843-854. doi:10.1016/0092-8674(93)90529-Y

20. Pasquinelli AE, Reinhart BJ, Slack F, et al. Conservation of the sequence and temporal expression of let-7 heterochronic regulatory RNA. Nature. 2000;408:86-88. doi:10.1038/35040556

21. Gaudet AD, Fonken LK, Watkins LR, Nelson RJ, Popovich PG. MicroRNAs: roles in regulating neuroinflammation. Neuroscientist. 2017;24:221-245. doi:10.1177/1073858417721150

22. Miller BH, Wahlestedt C. MicroRNA dysregulation in psychiatric disease. Brain Res. 2010;1338:89-99. doi:10.1016/j.brainres.2010.03.035

23. Mehta A, Baltimore D. MicroRNAs as regulatory elements in immune system logic. Nat Rev Immunol. 2016;16:279-294. doi:10.1038/nri.2016.40

24. Wang H, Peng W, Ouyang X, Li W, Dai Y. Circulating microRNAs as candidate biomarkers in patients with systemic lupus erythematosus. Transl Res. 2012;160:198-206. doi:10.1016/j.trsl.2012.04.002

25. Redis RS, Calin, Yang Y, You MJ, Calin GA. Cell-to-cell miRNA transfer: from body homeostasis to therapy. Pharmacol Ther. 2012;136:169-174. doi:10.1016/j.pharmthera.2012.08.003

26. Keller A, Leidinger $\mathrm{P}$, Bauer $\mathrm{A}$, et al. Toward the blood-borne miRNome of human diseases. Nat Methods. 2011;8:841-843. doi:10.1038/nmeth.1682

27. Erakov EA, Ivanova SA, Buneva VN, Nevinsky GA. Hydrolysis by catalytic IgGs of microRNA specific for patients with schizophrenia. IUBMB Life. 2018;70:153-164. doi:10.1002/iub.1712

28. Ermakov EA, Ivanova SA, Buneva VN, Nevinsky GA. Bloodderived RNA- and microRNA-hydrolyzing IgG antibodies in schizophrenia patients. Biochemistry. 2018;83:507-526. doi:10.1134/ S0006297918050048

29. Ermakov EA, Smirnova LP, Parkhomenko TA, et al. DNAhydrolysing activity of IgG antibodies from the sera of patients with schizophrenia. Open Biol. 2015;5:150064. doi:10.1098/ rsob.150064

30. Parshukova D, Sedykh S, Smirnova L, et al. Study of the level of IgG to myelin basic protein and their catalytic activity in schizophrenic patients. Eur Neuropsychopharmacol. 2016;26:S215-S216. doi:10.10 16/S0924-977X(16)31066-5

31. Parshukova D, Smirnova LP, Ermakov EA, et al. Autoimmunity and immune system dysregulation in schizophrenia: igGs from sera of patients hydrolyze myelin basic protein. J Mol Recognit. 2019;32: e2759. doi:10.1002/jmr.2759

32. http://the-newspapers.com/2017/11/08/schizophrenia-has-announced -a-disease-of-the-immune-system.

33. O'Connor KC, Bar-Or A, Hafler DA. The neuroimmunology of multiple sclerosis: possible roles of $\mathrm{T}$ and $\mathrm{B}$ lymphocytes in immunopathogenesis. J Clin Immunol. 2001;21:81-92. doi:10.1023/ A:1011064007686

34. Polosukhina DI, Kanyshkova TG, Doronin BM, et al. Hydrolysis of myelin basic protein by polyclonal catalytic IgGs from the sera of patients with multiple sclerosis. J Cell Mol Med. 2004;8:359-368. doi:10.1111/j.1582-4934.2004.tb00325.x 
35. Polosukhina DI, Kanyshkova TG, Doronin BM, et al. Metaldependent hydrolysis of myelin basic protein by IgGs from the sera of patients with multiple sclerosis. Immunol Lett. 2006;103:75-81. doi:10.1016/j.imlet.2005.10.018

36. Bezuglova AV, Konenkova LP, Doronin BM, Buneva VN, Nevinsky GA. Affinity and catalytic heterogeneity and metal-dependence of polyclonal myelin basic protein-hydrolyzing IgGs from sera of patients with systemic lupus erythematosus. J Mol Recognit. 2011;24:960-974. doi:10.1002/jmr.1143

37. Vlassov A, Florentz C, Helm M, et al. Characterization and selectivity of catalytic antibodies from human serum with RNase activity. Nucl Acid Res. 1998;26:5243-5250. doi:10.1093/nar/ 26.23.5243

38. Vlasov AV, Baranovskii AG, Kanyshkova TG, et al. Substrate specificity of serum DNA- and RNA-hydrolyzing antibodies of patients with polyarthritis and autoimmune thyroiditis. Mol Biol. 1998;32:559-569.

39. Vlasov AV, Helm M, Naumov VA, et al. Features of tRNA hydrolysis by autoantibodies from blood serum of patients with certain autoimmune and virus diseases. Mol Biol. 1999;33:866-872.

40. O'Connell RM, Kahn D, Gibson WS, et al. MicroRNA-155 promotes autoimmune inflammation by enhancing inflammatory $\mathrm{T}$ cell development. Immunity. 2010;33(4):607-619. doi:10.1016/j.immuni. 2010.09.009

41. Thai TH, Calado DP, Casola S, et al. Regulation of the germinal center response by microRNA-155. Science. 2007;316 (5824):604-608. doi:10.1126/science.1141229

42. Du C, Liu C, Kang J, et al. MicroRNA miR-326 regulates T H-17 differentiation and is associated with the pathogenesis of multiple sclerosis. Nat Immunol. 2009;10:1252-1259. doi:10.1038/ni. 1798

43. Liang D, Shen N. MicroRNA involvement in lupus: the beginning of a new tale. Curr Opin Rheumatol. 2012;24(5):489-498. doi:10.1097/ BOR.0b013е3283563363ю

44. Shen N, Liang D, Tang Y, De Vries N, Tak PP. MicroRNAsnovel regulators of systemic lupus erythematosus pathogenesis. Nat Rev Rheumatol. 2012;8(12):701-709. doi:10.1038/nrrheum. 2012.14

45. Chen JQ, Papp G, Póliska S, et al. MicroRNA expression profiles identify disease-specific alterations in systemic lupus erythematosus and primary Sjögren's syndrome. PLoS One. 2017;12(3):e0174585. doi:10.1371/journal.pone.0174585

46. Tang Y, Luo X, Cui H, et al. MicroRNA-146a contributes to abnormal activation of the type I interferon pathway in human lupus by targeting the key signaling proteins. Arthritis Rheum. 2009;60 (4):1065-1075. doi:10.1002/art.24436

47. Sun XG, Tao JH, Xiang N, et al. Negative correlation between miR-326 and Ets-1 in regulatory $\mathrm{T}$ cells from new-onset SLE patients. Inflammation. 2016;39(2):822-829. doi:10.1007/s10753016-0312-8

48. Cao DD, Li L, Chan WY. MicroRNAs: key regulators in the central nervous system and their implication in neurological diseases. Int J Mol Sci. 2016;17(6):842. doi:10.3390/ijms17060842

49. Wang Y, Han Z, Fan Y, et al. MicroRNA-9 inhibits NLRP3 inflammasome activation in human atherosclerosis inflammation cell models through the JAK1/STAT signaling pathway. Cell Physiol Biochem. 2017;41(4):1555-1571. doi:10.1159/000470822

50. Guo LM, Pu Y, Han Z, et al. MicroRNA-9 inhibits ovarian cancer

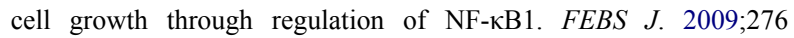
(19):5537-5546. doi:10.1111/j.1742-4658.2009.07237.x
51. Fredman G, Li Y, Dalli J, Chiang N, Serhan CN. Self-limited versus delayed resolution of acute inflammation: temporal regulation of pro-resolving mediators and microRNA. Sci Rep. 2012;2(1):1-9. doi:10.1038/srep00639

52. Paul S, Volle DJ, Beach CM, Johnson DR, Powell MJ, Massey RJ. Catalytic hydrolysis of vasoactive intestinal peptide by human autoantibody. Science. 1989;244:1158-1162. doi:10.1126/science. 2727702

53. Shumnalieva R, Kachakova D, Shoumnalieva-Ivanova V, Miteva P, Kaneva R, Monov S. Whole peripheral blood miR-146a and miR-155 expression levels in systemic lupus erythematosus patients. Acta Reumatol Port. 2018;3:217-225.

54. Majd M, Hosseini A, Ghaedi K, Kiani-Esfahani A, Tanhaei S, Shiralian-Esfahani H. Nasr-Esfahani. MiR-9-5p and miR-106a-5p dysregulated in CD4+ T-cells of multiple sclerosis patients and targeted essential factors of $\mathrm{T}$ helper17/regulatory T-cells differentiation. Iran $J$ Basic Med Sci. 2018;21:277-283. doi:10.22038/ijbms.2018.25382.6275

55. Xu L, Bai SY, Zhang LM, et al. MicroRNA-9 influence lupus nephritis by targeting STK3 related MAPK signaling transduction pathway. Int J Clin Exp Pathol. 2017;10:2784-2793.

56. Xia Y, Tao JH, Fang X, et al. MicroRNA-326 upregulates b cell activity and autoantibody production in lupus disease of MRL/lpr mice. Mol Ther Nucleic Acids. 2018;11:284-291. doi:10.1016/j. omtn.2018.02.010

57. Thiele S, Wittmann J, Jäck HM, Pahl A. MiR-9 enhances IL-2 production in activated human CD4+ T cells by repressing Blimp-1. Eur J Immunol. 2012;42:2100-2108. doi:10.1002/eji.201142203

58. Lehmann SM, Krüger C, Park B, et al. An unconventional role for miRNA: let-7 activates Toll-like receptor 7 and causes neurodegeneration. Nat Neurosci. 2012;15(6):827-835. doi:10.1038/ nn.3113

59. Bartok E, Hartmann G. Immune sensing mechanisms that discriminate self from altered self and foreign nucleic acids. Immunity. 2020;53(1):54-77. doi:10.1016/j.immuni.2020.06.014

60. Ostendorf T, Zillinger T, Andryka K, et al. Immune sensing of synthetic, bacterial, and protozoan RNA by toll-like receptor 8 requires coordinated processing by RNase T2 and RNase 2 . Immunity. 2020;52(4):591-605. doi:10.1016/j.immuni.2020.03.009

61. Kosugi I, Muro H, Shirasawa H, Ito I. Endocytosis of soluble IgG immune complex and its transport to lysosomes in hepatic sinusoidal endothelial cells. J Hepatol. 1992;16(12):106-114. doi:10.1016/ S0168-8278(05)80102-3

62. Ukkonen P, Lewis V, Marsh M, Helenius A, Mellman I. Transport of macrophage Fc receptors and Fc receptor-bound ligands to lysosomes. J Exp Med. 1986;163(4):952-971. doi:10.1084/jem.163.4.952

63. Inoue $\mathrm{K}$, Ishizawa $\mathrm{M}$, Kubota $\mathrm{T}$. Monoclonal anti-dsDNA antibody 2C10 escorts DNA to intracellular DNA sensors in normal mononuclear cells and stimulates secretion of multiple cytokines implicated in lupus pathogenesis. Clin Exp Immunol. 2020;199 (2):150-162. doi:10.1111/cei.13382

64. Slastnikova TA, Ulasov AV, Rosenkranz AA, Sobolev AS. Targeted intracellular delivery of antibodies: the state of the art. Front Pharmacol. 2018;9:1208. doi:10.3389/fphar.2018.01208

65. Jang JY, Jeong JG, Jun HR, et al. A nucleic acid-hydrolyzing antibody penetrates into cells via caveolae-mediated endocytosis, localizes in the cytosol and exhibits cytotoxicity. Cell Mol Life Sci. 2009;66(1112):1985-1997. doi:10.1007/s00018-009-9179-2 


\section{Publish your work in this journal}

The Journal of Inflammation Research is an international, peerreviewed open-access journal that welcomes laboratory and clinical findings on the molecular basis, cell biology and pharmacology of inflammation including original research, reviews, symposium reports, hypothesis formation and commentaries on: acute/chronic inflammation; mediators of inflammation; cellular processes; molecula mechanisms; pharmacology and novel anti-inflammatory drugs; clinical conditions involving inflammation. The manuscript management system is completely online and includes a very quick and fair peerreview system. Visit http://www.dovepress.com/testimonials.php to read real quotes from published authors.

Submit your manuscript here: https://www.dovepress.com/journal-of-inflammation-research-journal 